Article

\title{
Mixed Sr and Ba Tri-Stannides/Plumbides $A^{\mathrm{II}}\left(\mathbf{S n}_{1-x} \mathbf{P b}_{x}\right)_{3}$
}

\author{
Michael Langenmaier ${ }^{\dagger} \ddagger$, Michael Jehle ${ }^{\dagger, \ddagger}$ and Caroline Röhr * (D) \\ Institut für Anorganische und Analytische Chemie, Albert-Ludwigs-Universität Freiburg, 79104 Freiburg, \\ Germany; michil@limonite.chemie.uni-freiburg.de (M.L.); michij@almandine.chemie.uni-freiburg.de (M.J.) \\ * Correspondence: caroline@ruby.chemie.uni-freiburg.de; Tel.: +49-0761-203-6143 \\ † These authors contributed equally to this work. \\ $\ddagger$ Institut für Anorganische und Analytische Chemie, Albert-Ludwigs-Universität Freiburg, Albertstr. 21, \\ D-79104 Freiburg, Germany.
}

Received: 2 April 2018 ; Accepted: 26 April 2018; Published: 4 May 2018

Abstract: The continuous substitution of tin by lead $\left(M^{\mathrm{IV}}\right)$ allows for the exploration geometric criteria for the stability of the different stacking variants of alkaline-earth tri-tetrelides $A^{\mathrm{II}} M_{3}^{\mathrm{IV}}$. A series of ternary $\mathrm{Sr}$ and Ba mixed tri-stannides/plumbides $A^{\mathrm{II}}\left(\mathrm{Sn}_{1-x} \mathrm{~Pb}_{x}\right)_{3}\left(A^{\mathrm{II}}=\mathrm{Sr}, \mathrm{Ba}\right)$ was synthesized from stoichiometric mixtures of the elements. Their structures were determined by means of single crystal X-ray data. All structures exhibit close packed ordered $A M_{3}$ layers containing $M$ kagomé nets. Depending on the stacking sequence, the resulting $M$ polyanion resembles the oxygen substructure of the hexagonal (face-sharing octahedra, $h$ stacking, $\mathrm{Ni}_{3} \mathrm{Sn}$-type, border compound $\mathrm{BaSn}_{3}$ ) or the cubic (corner-sharing octahedra, $c$ stacking, $\mathrm{Cu}_{3} \mathrm{Au}$-type, border compound $\mathrm{SrPb}_{3}$ ) perovskite. In the binary compound $\mathrm{BaSn}_{3}\left(\mathrm{Ni}_{3} \mathrm{Sn}\right.$-type) up to $28 \%$ of $\mathrm{Sn}$ can be substituted against $\mathrm{Pb}\left(\mathrm{hP} 8, \mathrm{~Pb}_{3} / \mathrm{mmc}\right.$, $x=0.28(4): a=726.12(6), c=556.51(6) \mathrm{pm}, R 1=0.0264)$. A further increased lead content of 47 to $66 \%$ causes the formation of the $\mathrm{BaSn}_{2.57} \mathrm{Bi}_{0.43}$-type structure with a $(h h h c)_{2}$ stacking $\left[h P 32, P 6_{3} / m m c\right.$, $x=0.47(3): a=726.80(3), c=2235.78(14) \mathrm{pm}, R 1=0.0437]$. The stability range of the $\mathrm{BaPb}_{3}-\mathrm{type}$ sequence $(h h c)_{3}$ starts at a lead proportion of $78 \%(h R 36, R \overline{3} m, a=728.77(3), c=2540.59(15) \mathrm{pm}$, $R 1=0.0660$ ) and reaches up to the pure plumbide $\mathrm{BaPb}_{3}$. A second new polymorph of $\mathrm{BaPb}_{3}$ forms the $\mathrm{Mg}_{3}$ In-type structure with a further increased amount of cubic sequences $\left[(h h c c)_{3} ; h R 48\right.$, $a=728.7(2), c=3420.3(10) \mathrm{pm}, R 1=0.0669]$ and is thus isotypic with the border phase $\mathrm{SrSn}_{3}$ of the respective strontium series. For the latter, a $\mathrm{Pb}$ content of $32 \%$ causes a small existence region of the $\mathrm{PuAl}_{3}$-type structure $\left[h P 24, P 6_{3} / m m c, a=696.97(6), c=1675.5(2) \mathrm{pm}, R 1=0.1182\right]$ with a $(h c c)_{2}$ stacking. The series is terminated by the pure $c$ stacking of $\mathrm{SrPb}_{3}$, the stability range of this structure type starts at $75 \% \mathrm{~Pb}(c P 4, P m \overline{3} m ; a=495.46(9) \mathrm{pm}, R 1=0.0498)$. The stacking of the close packed layers is evidently determined by the ratio of the atomic radii of the contributing elements. The $\mathrm{Sn} / \mathrm{Pb}$ distribution inside the polyanion ('coloring') is likewise determined by size criteria. The electronic stability ranges, which are discussed on the basis of the results of FP-LAPW band structure calculations are compared with the Zintl concept and Wade's / mno electron counting rules. Still, due to the presence of only partially occupied steep $M-p$ bands the compounds are metals exhibiting pseudo band gaps close to the Fermi level. Thus, this structure family represents an instructive case for the transition from polar ionic/covalent towards (inter)metallic chemistry.

Keywords: stannides; plumbides; alkaline-earth

\section{Introduction}

In view of the complex bonding situation between ionic, covalent and metallic, the synthetic, crystallographic and bond theoretical studies on geometric and electronic parameters determining 
the structure chemistry (and therewith also the properties) of polar intermetallics of the alkali and alkaline-earth compounds of the $p$-block elements are still a fascinating field of research. Compared to the vast number of alkali/alkaline-earth stannides and plumbides [1], which are simple electron-precise Zintl phases, the tri-stannides and -plumbides $A \mathrm{Sn}_{3}$ and $A \mathrm{~Pb}_{3}$ of the alkaline-earth elements $(A=\mathrm{Ca}, \mathrm{Sr}, \mathrm{Ba})$ are ordered derivatives of simple dense packings of the two elements [2-9]. Similar to the variation of the alkaline-earth elements $(A)$ in the pure tri-stannides [10] and tri-plumbides [11], a continuous substitution of tin by lead allows for the exploration of geometric and electronic $(\mathrm{Sn} / \mathrm{Pb}$ distribution) criteria for the stability of different stacking variants of the hexagonal close packed layers $\left[A M_{3}\right]$ in these tri-tetrelides $A^{\mathrm{II}} M^{\mathrm{IV}}{ }_{3}$.

The tri-plumbides $A \mathrm{~Pb}_{3}$ of calcium and strontium, which both form the cubic $\mathrm{Cu}_{3} \mathrm{Au}$-type structure (|:ABC:| or $c$ stacking after Jagodzinski), have been structurally characterized using X-ray powder data in the past and some physical properties as well as the electronic band structure were reported in the 1960s and 1970s by Havinga et al. $[6,12,13]$. More recent works on their electronic and magnetic properties were published by Baranovskiy et al. [14,15]. The structure of the binary barium plumbide $\mathrm{BaPb}_{3}\left[(h h c)_{3}\right.$ stacking] was derived and refined from 78 reflections by Sands, Wood and Ramsey as early as 1964 [9]. Only two years later, van Vucht published an elaborate work [7], in which he, based on powder diffraction data, already suggested the existence of further stacking variants for the mixed alkaline-earth plumbides $A_{x} \mathrm{Ba}_{1-x} \mathrm{~Pb}_{3}(A=\mathrm{Ca}$, Sr). These two series have been fully explored by our group 10 years ago [11]: Both the $\mathrm{Ca}$ and the $\mathrm{Sr}$ series start with the pure $c$ stacking of $(\mathrm{Ca} / \mathrm{Sr}) \mathrm{Pb}_{3}$. At an approximate 1:1 ratio of strontium and barium (e.g., 35 to $53 \% \mathrm{Sr}$ ) the $\mathrm{PuAl}_{3}$-type $\left[(h c c)_{2}\right.$ stacking] has a distinct homogeneity range. Reversely, the $(h h c)_{3}$ stacking of the binary compound $\mathrm{BaPb}_{3}$ changes at an already very small partial substitution of barium against calcium $\left(\mathrm{Ca}_{0.03} \mathrm{Ba}_{0.97} \mathrm{~Pb}_{3}\right)$ or strontium $\left(\mathrm{Sr}_{0.11} \mathrm{Ba}_{0.89} \mathrm{~Pb}_{3}\right)$ towards the (hhcc) $)_{3}$ sequence of the $\mathrm{Mg}_{3}$ In-type.

For the tri-stannides $A \mathrm{Sn}_{3}$, the continuous substitution of the different alkaline-earth cations against each other has been likewise investigated in a systematic study [10]: Starting from $\mathrm{CaSn}_{3}$ (pure $c$ stacking [2]) up to $46 \%$ of Ca can be substituted against Sr without a structural change. The binary phase $\mathrm{SrSn}_{3}$ forms the $\mathrm{Mg}_{3}$ In-type structure with a $(h h c c)_{3}$ stacking sequence [3]. A small partial substitution of Sr against Ba (9 to 19\%) causes the packing to switch to the $(h h c)_{3}$ sequence of the $\mathrm{BaPb}_{3}$-type. At a Ba proportion of $26 \%$ a further structure change to the $\mathrm{BaSn}_{2.57} \mathrm{Bi}_{0.43}$-type structure $\left[(h h h c)_{2}\right.$ stacking] takes place. The tin series terminates with the pure $h$ stacking of $\mathrm{BaSn}_{3}$; the stability range of this $\mathrm{Ni}_{3} \mathrm{Sn}$-type structure starts at the composition $\mathrm{Sr}_{0.22} \mathrm{Ba}_{0.78} \mathrm{Sn}_{3}$.

Beyond these pure geometric/size effects, van Vucht and Havinga $[8,16]$ also demonstrated the electronic influence on the $h / c$ stacking of the layers in several Tl-substituted plumbides $A(\mathrm{Tl} / \mathrm{Pb})_{3}$. An indium content in $\mathrm{Ba}(\mathrm{In} / \mathrm{Pb})_{3}$ of $15 \%$ also changes the stacking from the simple cubic to the mixed $(h c c)_{2}$ sequence of the $\mathrm{PuAl}_{3}$-type [17]. For the electron-richer system $\mathrm{BaSn}_{3}-\mathrm{BaBi}_{3}$ a similar influence of the valence electron (v.e.) number on the stacking was shown more recently by Fässler et al. [18].

In the present work, we report on the results of a systematic experimental, crystallographic and bond-theoretical DFT investigation of mixed $\mathrm{Sn} / \mathrm{Pb}$ tri-tetrelides of $\mathrm{Sr}$ and Ba. Here, the substitution of tin by lead does not only change the geometric relations, but in addition the occupation of the crystallographically different $M$ positions of the more complex stacked sequences with tin and/or lead, i.e., the 'coloring' of the polyanion [19] can be studied.

\section{Experimental}

\subsection{Synthesis and Phase Widths}

The synthesis of the mixed $\mathrm{Sn} / \mathrm{Pb}$ tri-tetrelides was generally performed starting from the elements strontium or barium, tin and lead as obtained from commercial sources ( $\mathrm{Sr}, \mathrm{Ba}$ : Metallhandelsgesellschaft Maassen, Bonn, 99\%; Sn: shots, 99.9\%, Riedel de Häen; Pb: powder, $99.9 \%$, Merck KGaA). The elements were filled into tantalum crucibles in a glovebox under an argon atmosphere and the sealed containers were heated up with a rate of $200{ }^{\circ} \mathrm{C} / \mathrm{h}$ to maximum 
temperatures $\left(T_{\max }\right)$ of 700 to $800{ }^{\circ} \mathrm{C}$. For all samples, the crystallization was performed by a slow cooling rate $\left(\dot{T}^{\downarrow}\right)$ of 2 to $20{ }^{\circ} \mathrm{C} / \mathrm{h}$. The maximum temperatures applied and the detailed cooling rates can be found in Table 1, together with the weighed sample compositions, which were mainly restricted to the stoichiometric 1:3 [for $(\mathrm{Sr} / \mathrm{Ba}):(\mathrm{Sn} / \mathrm{Pb})$ ] element ratio. All sample reguli were hard and brittle with a dark-metallic luster and are sensitive against moisture. Representative parts of the reguli were ground and sealed in capillaries with a diameter of $0.3 \mathrm{~mm}$. X-ray powder patterns were collected on transmission powder diffraction systems (STADI-P or Dectris Mythen 1K detector, Stoe \& Cie, Darmstadt, $\mathrm{MoK}_{\alpha}$ radiation, graphite monochromator). For the phase analysis, the measured powder patterns were compared to the calculated (program LAZY-PULVERIX [20]) reflections of the title compounds and other known phases in the respective ternary systems.

Table 1. Details of the synthesis of the title compounds (cf. Tables 2 and 3 for the single crystal numbers; uniform heating rate: $\dot{T}^{\uparrow}=200{ }^{\circ} \mathrm{C} / \mathrm{h}$ ) .

\begin{tabular}{|c|c|c|c|c|c|c|c|c|c|c|c|c|c|c|}
\hline \multirow{2}{*}{$\frac{\text { Sample }}{\text { Composition }}$} & \multirow{2}{*}{$\begin{array}{l}\text { Structure } \\
\text { Type }\end{array}$} & \multirow{2}{*}{$\begin{array}{l}\text { Single } \\
\text { Crystal }\end{array}$} & \multirow{2}{*}{$\frac{\mathrm{Pb}}{\text { Content }}$} & \multicolumn{6}{|c|}{ Weighed Elements } & \multicolumn{5}{|c|}{ Temperature Program } \\
\hline & & & & \multicolumn{2}{|c|}{$\mathrm{Sr} / \mathrm{Ba}$} & \multicolumn{2}{|r|}{ Sn } & \multicolumn{2}{|r|}{$\mathbf{P b}$} & $T_{\max }$ & $\dot{T}^{\downarrow}$ & $\dot{T}^{\downarrow}$ & $T$ & $\dot{T}^{\downarrow}$ \\
\hline & & No. & {$[\%]$} & {$[\mathrm{mg}]$} & [mmol] & {$[\mathrm{mg}]$} & [mmol] & {$[\mathrm{mg}]$} & [mmol] & \multicolumn{5}{|c|}{ (in $\left[{ }^{\circ} \mathrm{C}\right]$ and $\left.\left[{ }^{\circ} \mathrm{C} / \mathrm{h}\right]\right)$} \\
\hline $\mathrm{BaSn}_{2} \mathrm{~Pb}$ & $\mathrm{Ni}_{3} \mathrm{Sn}$ & 1 & 28 & 253.7 & 1.85 & 407.0 & 3.43 & 356.8 & 1.72 & 750 & 30 & 500200 & & \\
\hline $\mathrm{BaSn}_{1.5} \mathrm{~Pb}_{1.5}$ & $\mathrm{BaSn}_{26} \mathrm{Bi}_{0.4}$ & 2 & 47.4 & 220.7 & 1.61 & 284.7 & 2.40 & 496.7 & 2.40 & 750 & 200 & $650 \quad 2$ & 500 & 200 \\
\hline $\mathrm{BaSnPb}_{2}$ & $\mathrm{BaSn}_{2,6} \mathrm{Bi}_{0.4}$ & 3 & 66.3 & 205.2 & 1.49 & 176.0 & 1.48 & 619.4 & 2.99 & 750 & 20 & $500 \quad 200$ & & \\
\hline $\mathrm{BaSn}_{0.75} \mathrm{~Pb}_{2.25}$ & $\mathrm{BaPb}_{3}$ & 4 & 78.3 & 199.6 & 1.45 & 129.1 & 1.09 & 675.9 & 3.26 & 750 & 200 & 6502 & 500 & 200 \\
\hline $\mathrm{BaSn}_{0.5} \mathrm{~Pb}_{2.5}$ & $\mathrm{BaPb}_{3}$ & $4 p$ & 85 & 192.2 & 1.40 & 88.1 & 0.74 & 724.3 & 3.50 & 750 & 30 & $500 \quad 200$ & & \\
\hline $\mathrm{BaGePb}_{2}$ & $\mathrm{Mg}_{3} \mathrm{In}$ & 5 & 100 & 220.6 & 1.61 & 116.9 & 1.61 & 663.6 & 3.20 & 750 & 30 & 500200 & & \\
\hline$\overline{\mathrm{SrSn}_{2}}$ & $\mathrm{Mg}_{3}$ In & $5 p$ & 14 & 179.7 & 2.05 & 608.8 & 5.13 & 212.3 & 1.02 & 800 & 200 & $750 \quad 2$ & 625 & 200 \\
\hline $\mathrm{SrSn}_{2} \mathrm{~Pb}$ & $\mathrm{PuAl}_{3}$ & 6 & 32 & 164.8 & 1.88 & 445.5 & 3.75 & 389.6 & 1.88 & 800 & 200 & $750 \quad 2$ & 625 & 200 \\
\hline $\mathrm{SrSn}_{1,5} \mathrm{~Pb}_{15}$ & $\mathrm{PuAl}_{3}$ & $6 \mathrm{p}$ & 34 & 152.0 & 1.73 & 307.9 & 2.59 & 539.0 & 2.60 & 700 & 20 & $500 \quad 200$ & & \\
\hline $\mathrm{SrSn}_{0.75}{ }^{1.3} \mathrm{~Pb}_{2.25}$ & $\mathrm{Cu}_{3} \mathrm{Au}$ & 7 & 75 & 137.1 & 1.56 & 138.7 & 1.17 & 726.0 & 3.50 & 700 & 20 & $500 \quad 200$ & & \\
\hline
\end{tabular}

Starting from the pure tin compound, the first ternary sample of the Ba series, with an overall composition of $\mathrm{BaSn}_{2} \mathrm{~Pb}$, yielded the border phase $\mathrm{BaSn}_{2.16} \mathrm{~Pb}_{0.84}(\mathbf{1})$ of the $\mathrm{Ni}_{3} \mathrm{Sn}$-type (magenta bar in Figure 1) in pure phase. The powder pattern of the samples with a Pb content of $50 \%$ and $66.7 \%$ could be fully indexed with the data of the $\mathrm{BaSn}_{2.6} \mathrm{Bi}_{0.4}$-type. Accordingly, the two border phases of the existence range of this structure type (dark blue bar in Figure 1), $\mathrm{BaSn}_{1.58} \mathrm{~Pb}_{1.42}$ (2) and $\mathrm{BaSn}_{1.01} \mathrm{~Pb}_{1.99}$ (3), were obtained from these two samples. The following two samples with a further increased lead content, $\mathrm{BaSn}_{0.75} \mathrm{~Pb}_{2.25}$ and $\mathrm{BaSn}_{0.5} \mathrm{~Pb}_{2.5}$, yielded ternary $\mathrm{Sn}$-containing variants of the known $\mathrm{BaPb}_{3}$-type structure (cyan). The refined chemical composition of the border phase obtained from the first sample, $\mathrm{BaSn}_{0.65} \mathrm{~Pb}_{2.35}(4)$, is very close to the weighed sample stoichiometry, the composition of the somewhat $\mathrm{Pb}$-richer phase was refined from powder data. A second form of $\mathrm{BaPb}_{3}$, which is isostructural to $\mathrm{SrSn}_{3}$ (green bar in Figure 1), was obtained for the first time from the Ge-containing sample $\left(\mathrm{BaGePb}_{2}\right)$, which contains (optically visible) elemental germanium as a second product. In the Sr series, a lead content of $17 \%\left(\mathrm{SrSn}_{2.5} \mathrm{~Pb}_{0.5}\right)$ still yielded the $\mathrm{Mg}_{3}$ In-type structure of the binary tri-stannide $\mathrm{SrSn}_{3}$. The composition of this phase $\left(\mathrm{SrSn}_{2.58} \mathrm{~Pb}_{0.42}\right)$ was refined from powder data (Section 2.3). The two samples with an Sn-content of 66 and 50\% contain $\mathrm{PuAl}_{3}$-type phases. For the first sample, the single crystal data of selected crystals are in very good agreement with the weighed element ratio (6: $\mathrm{SrSn}_{2.05} \mathrm{~Pb}_{0.95}$, Section 2.2). Due to the low crystal quality, the composition of the $\mathrm{Pb}$-richer phase of this type could be only refined from powder data (Section 2.3). A small content of the $\mathrm{Pb}$-richer cubic $\mathrm{Cu}_{3} \mathrm{Au}$-type phase, which is formed in $\mathrm{X}$-ray pure form in the final sample $\mathrm{SrSn}_{0.75} \mathrm{~Pb}_{2.25}$, could not be excluded due to the overlap of the few reflections of the $\mathrm{Cu}_{3} \mathrm{Au}$-type with those of the structurally related $\mathrm{PuAl}_{3}$-type.

\subsection{Single Crystal Structure Refinements}

For the crystal structure refinements (cf. Tables 2 and 3), irregularly shaped single crystals were selected using a stereo microscope and mounted in glass capillaries (diameter $0.1 \mathrm{~mm}$ ) under dried 
paraffine oil. The crystals were centered on diffractometers equipped with an image plate (Stoe IPDS, sealed tube) or a CCD detector (Bruker Apex-II Quazar, microfocus source).

Table 2. Crystallographic data and details of the data collection and structure refinement of the compounds of the barium series $\mathrm{BaSn}_{2.16} \mathrm{~Pb}_{0.84}$ (1), $\mathrm{BaSn}_{1.58} \mathrm{~Pb}_{1.42}$ (2), $\mathrm{BaSn}_{1.01} \mathrm{~Pb}_{1.99}$ (3), $\mathrm{BaSn}_{0.65} \mathrm{~Pb}_{2.35}$ (4), and $\mathrm{BaPb}_{3}$ (5) and the strontium compounds $\mathrm{SrSn}_{2.05} \mathrm{~Pb}_{0.95}$ (6) and $\mathrm{SrSn}_{0.75} \mathrm{~Pb}_{2.25}$ (7).

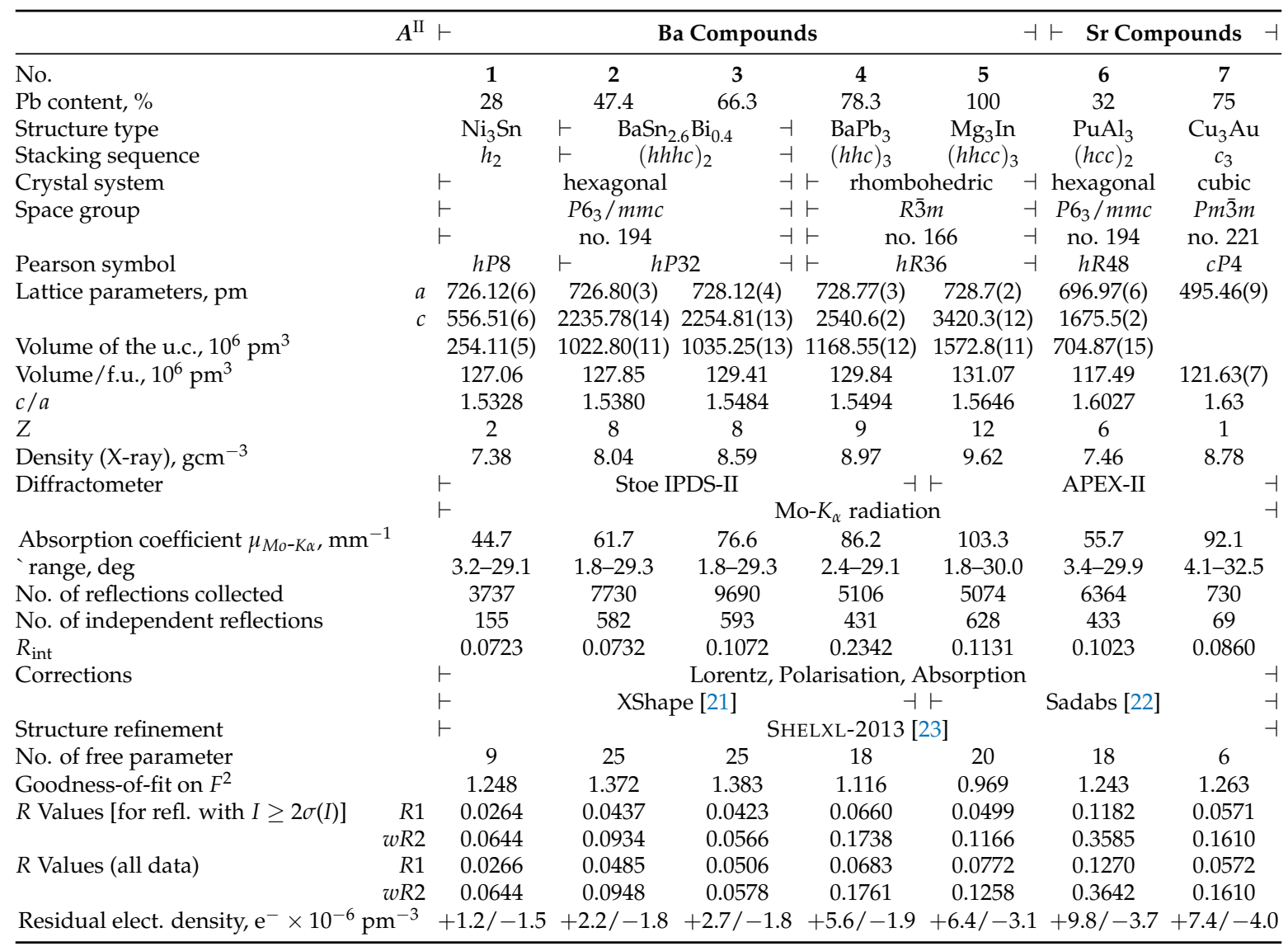

The reflections of the tin-rich compounds of the Ba series could be indexed by the expected small hexagonal cell of the $\mathrm{Ni}_{3} \mathrm{Sn}$ type (space group $\mathrm{P}_{3} / \mathrm{mmc}$ ). The border compound of the stability range of this structure type, $\mathrm{BaSn}_{2.16} \mathrm{~Pb}_{0.84}(\mathbf{1})$, was obtained in pure phase from a sample of overall composition $\mathrm{BaSn}_{2} \mathrm{~Pb}$. The parameters of the structure model of the pure tri-stannide [5] were refined using the program SHELXL-2013 [23], and the mixed $\mathrm{Sn} / \mathrm{Pb}$ position was treated with constrained positional and anisotropic displacement parameters (ADPs). The obtained formula $\mathrm{BaSn}_{2.16} \mathrm{~Pb}_{0.84}$ is only slightly Sn-richer than the sample composition. Crystals yielded from the lead-richer samples $\mathrm{BaSn}_{1.58} \mathrm{~Pb}_{1.42}$ and $\mathrm{BaSn}_{1.01} \mathrm{~Pb}_{1.99}$ show a similar hexagonal basis and the same extinction conditions, but the length of the hexagonal $c$ axis increases to about $2200 \mathrm{pm}$, which indicates the formation of the $\mathrm{BaSn}_{2.6} \mathrm{Bi}_{0.4}$-type structure [18]. The two border compounds of the stability range of this structure type contain 47.4 (2) and $66.3 \%$ (3) lead, which is again close to the respective sample compositions. Accordingly, the powder patterns of these two samples are fully indexed with the data of the $\mathrm{BaSn}_{2.6} \mathrm{Bi}_{0.4}$-type. 
Table 3. Atomic coordinates and equivalent isotropic displacement parameters $\left(\mathrm{pm}^{2}\right)$ for the single crystal structures of the title compounds.

\begin{tabular}{|c|c|c|c|c|c|c|c|c|c|c|}
\hline Compound & No. & Atoms & $\begin{array}{l}\text { Wyckoff } \\
\text { Position }\end{array}$ & $\begin{array}{l}\text { Point Group } \\
\text { Symmetry }\end{array}$ & $\begin{array}{l}\text { Stacking } \\
\text { Sequence }\end{array}$ & $\begin{array}{c}\text { Pb Prop. } \\
/ \%\end{array}$ & $x$ & $y$ & $z$ & $U_{\text {equiv. }}$ \\
\hline $\mathrm{BaSn}_{2.16} \mathrm{~Pb}_{0.84}$ & 1 & $\begin{array}{l}\mathrm{Ba} \\
M\end{array}$ & $\begin{array}{l}2 d \\
6 h\end{array}$ & $\begin{array}{l}\overline{6} m 2 \\
m m 2\end{array}$ & $h$ & $28.0(14)$ & $\begin{array}{l}1 / 3 \\
0.14395(7)\end{array}$ & $\begin{array}{l}2 / 3 \\
2 x\end{array}$ & $\begin{array}{l}3 / 4 \\
1 / 4\end{array}$ & $\begin{array}{l}263(6) \\
244(4)\end{array}$ \\
\hline $\mathrm{BaSn}_{1.58} \mathrm{~Pb}_{1.42}$ & 2 & $\begin{array}{l}\mathrm{Ba}(1) \\
\mathrm{Ba}(2) \\
\mathrm{Ba}(3) \\
\mathrm{M}(1) \\
\mathrm{M}(2) \\
\mathrm{Pb}(3)\end{array}$ & $\begin{array}{c}2 a \\
2 b \\
4 f \\
6 h \\
12 k \\
6 g\end{array}$ & $\begin{array}{l}\overline{3} m . \\
\overline{6} m 2 \\
3 m . \\
m m 2 \\
. m . \\
\cdot \frac{2}{m} .\end{array}$ & $\begin{array}{l}h \\
h \\
c\end{array}$ & $\begin{array}{c}9.5(13) \\
40.1(12)\end{array}$ & $\begin{array}{l}0 \\
0 \\
1 / 3 \\
0.52781(12) \\
0.18965(8) \\
1 / 2\end{array}$ & $\begin{array}{l}0 \\
0 \\
2 / 3 \\
2 x \\
2 x \\
0\end{array}$ & $\begin{array}{l}0 \\
1 / 4 \\
0.13534(8) \\
1 / 4 \\
0.62443(4) \\
0\end{array}$ & $\begin{array}{l}250(6) \\
201(5) \\
176(4) \\
202(6) \\
227(4) \\
266(3)\end{array}$ \\
\hline $\mathrm{BaSn}_{1.01} \mathrm{~Pb}_{1.99}$ & 3 & $\begin{array}{l}\mathrm{Ba}(1) \\
\mathrm{Ba}(2) \\
\mathrm{Ba}(3) \\
\mathrm{M}(1) \\
\mathrm{M}(2) \\
\mathrm{Pb}(3)\end{array}$ & $\begin{array}{c}2 a \\
2 b \\
4 f \\
6 h \\
12 k \\
6 g\end{array}$ & $\begin{array}{l}\overline{3} m . \\
\overline{6} m 2 \\
3 m . \\
m m 2 \\
. m . \\
\cdot \frac{2}{m} .\end{array}$ & $\begin{array}{l}h \\
h \\
c\end{array}$ & $\begin{array}{l}23.7(1) \\
70.6(9)\end{array}$ & $\begin{array}{l}0 \\
0 \\
1 / 3 \\
0.52645(9) \\
0.18753(5) \\
1 / 2\end{array}$ & $\begin{array}{l}0 \\
0 \\
2 / 3 \\
2 x \\
2 x \\
0\end{array}$ & $\begin{array}{l}0 \\
1 / 4 \\
0.13465(6) \\
1 / 4 \\
0.62418(3) \\
0\end{array}$ & $\begin{array}{l}268(5) \\
211(5) \\
189(3) \\
210(4) \\
232(2) \\
262(2)\end{array}$ \\
\hline $\mathrm{BaSn}_{0.65} \mathrm{~Pb}_{2.35}$ & 4 & $\begin{array}{l}\mathrm{Ba}(1) \\
\mathrm{Ba}(2) \\
M(1) \\
\mathrm{Pb}(2)\end{array}$ & $\begin{array}{c}3 a \\
6 c \\
18 h \\
9 e\end{array}$ & $\begin{array}{l}\overline{3} m \\
3 m \\
. m \\
\cdot \frac{2}{m}\end{array}$ & $\begin{array}{l}h \\
c\end{array}$ & $67(2)$ & $\begin{array}{l}0 \\
0 \\
0.47707(12) \\
1 / 2\end{array}$ & $\begin{array}{l}0 \\
0 \\
-x \\
0\end{array}$ & $\begin{array}{l}0 \\
0.21602(10) \\
0.22315(4) \\
0\end{array}$ & $\begin{array}{l}374(9) \\
324(7) \\
364(6) \\
388(6)\end{array}$ \\
\hline $\mathrm{BaPb}_{3}$ & 5 & $\begin{array}{l}\mathrm{Ba}(1) \\
\mathrm{Ba}(2) \\
\mathrm{Pb}(1) \\
\mathrm{Pb}(2)\end{array}$ & $\begin{array}{c}6 c \\
6 c \\
18 h \\
18 h\end{array}$ & $\begin{array}{l}3 m \\
3 m \\
. m \\
. m\end{array}$ & $\begin{array}{l}h \\
c\end{array}$ & & $\begin{array}{l}0 \\
0 \\
0.47742(8) \\
0.50625(8)\end{array}$ & $\begin{array}{l}0 \\
0 \\
-x \\
-x\end{array}$ & $\begin{array}{l}0.13034(7) \\
0.28912(7) \\
0.12358(3) \\
0.29199(3)\end{array}$ & $\begin{array}{l}220(5) \\
234(5) \\
252(3) \\
297(3)\end{array}$ \\
\hline $\mathrm{SrSn}_{2.05} \mathrm{~Pb}_{0.95}$ & 6 & $\begin{array}{l}\operatorname{Sr}(1) \\
\operatorname{Sr}(2) \\
\operatorname{Sn}(1) \\
M(2)\end{array}$ & $\begin{array}{c}2 b \\
4 f \\
6 h \\
12 k\end{array}$ & $\begin{array}{c}\overline{6} m 2 \\
3 m . \\
m m 2 \\
. m .\end{array}$ & $\begin{array}{l}h \\
c\end{array}$ & $47(4)$ & $\begin{array}{l}0 \\
1 / 3 \\
0.5218(4) \\
0.16833(19)\end{array}$ & $\begin{array}{l}0 \\
2 / 3 \\
0.0436(8) \\
0.3367(4)\end{array}$ & $\begin{array}{l}1 / 4 \\
0.0930(5) \\
1 / 4 \\
0.58108(13)\end{array}$ & $\begin{array}{l}180(20) \\
185(18) \\
182(15) \\
221(11)\end{array}$ \\
\hline $\mathrm{SrSn}_{0.75} \mathrm{~Pb}_{2.25}$ & 7 & $\begin{array}{l}\mathrm{Sr} \\
M\end{array}$ & $\begin{array}{l}1 a \\
3 c\end{array}$ & $\begin{array}{l}m \overline{3} m \\
\frac{4}{m} m \cdot m\end{array}$ & $c$ & 75 & $\begin{array}{l}0 \\
0\end{array}$ & $\begin{array}{l}0 \\
1 / 2\end{array}$ & $\begin{array}{l}0 \\
1 / 2\end{array}$ & $\begin{array}{l}500(20) \\
159(9)\end{array}$ \\
\hline
\end{tabular}

The diffraction images of the crystals obtained from the Pb-rich sample $\mathrm{BaSn}_{0.5} \mathrm{~Pb}_{2.5}$ could be indexed by a rhombohedral lattice with the familiar unit cell basis of $730 \mathrm{pm}$, but now with a $c$ axis of $\approx 2500 \mathrm{pm}$, which indicates the formation of the $\mathrm{BaPb}_{3}$-type structure. During the single crystal refinement of this structure model, the $18 \mathrm{~h}$ position $M(1)$ turned out to be statistically occupied by tin and the final refinement yielded a Sn occupation of $67(2) \%$, i.e., an overall composition of $\mathrm{BaSn}_{0.65} \mathrm{~Pb}_{2.35}$ (4), which is again close to the weighed element ratios. For the likewise rhombohedral unit cell of the second form of $\mathrm{BaPb}_{3}-\mathrm{II}(5)$, the large $c$ axis indicated the 12-layer structure of the $\mathrm{Mg}_{3} \mathrm{In}$-type, which was also found for ternary derivatives of $\mathrm{BaPb}_{3}$ containing small amounts of $\mathrm{Ca}$ or $\mathrm{Sr}$ [11]. The structure refinement converged to $R 1$ values of 0.05 and the refinement as well as the unit cell volume (cf. the comparison in Section 3.1.4) gave no indication for an incorporation of germanium into the structure. All crystals of the Sr-series were of much lower quality than those of the Ba compounds and the diffraction images of crystals of different sizes all exhibit very broad reflections. Only the structure of the compound $\mathbf{6}\left(\mathrm{SrSn}_{2.05} \mathrm{~Pb}_{0.95}\right)$, which forms the hexagonal $\mathrm{PuAl}_{3}$-type, could be refined from single crystal data. However, a quite large value of $R 1$ and the residual electron density of about $+10 \mathrm{e}^{-} 10^{-6} \mathrm{pm}^{-3}$, which lies in the vicinity of the $M(2)$ position, result from the unsatisfactory quality of the diffraction data. In the case of the single crystals yielded from the sample $\mathrm{SrSn}_{0.75} \mathrm{~Pb}_{2.25}$ (7) the situation is even worse, and the $\mathrm{Sn}: \mathrm{Pb}$ ratio of the sole $M$ position in the cubic $\mathrm{Cu}_{3} \mathrm{Au}$-type structure had to be fixed to the weighed element ratio.

The data of the single crystal structure refinements, in which the $M$ sites are sorted according to increasing lead content (Table 3) and all atomic parameters were transformed to a standardized setting according to STRUCTURE TIDY [24], have been deposited [25]. 


\subsection{Rietveld Refinements}

The X-ray powder data used for the full-pattern Rietveld refinements were collected on the above mentioned powder diffractometer (Dectris Mythen $1 \mathrm{~K}$ detector) in the $2 \Theta$ range 2 to $41.8^{\circ}$ with a step width of $1.17^{\circ}$ and an exposure time of $180 \mathrm{~s} /$ step. The Rietveld refinements were performed using the programs GSAS [26] and EXPGUI [27].

The powder pattern of the sample $\mathrm{SrPb}_{0.5} \mathrm{Sn}_{2.5}(5 \mathrm{p})$ could be fully indexed and refined starting from the crystal data of $\mathrm{SrSn}_{3}\left(\mathrm{Mg}_{3} \mathrm{In}\right.$-type [28]). The obtained lattice parameters $(a=696.50(6)$, $c=3324.9(5) \mathrm{pm}, V /$ f.u. $=116.4 \times 10^{6} \mathrm{pm}^{3}$ ), which are somewhat larger than those of the binary compound $\mathrm{SrSn}_{3}(a=694.0, c=3301.0 \mathrm{pm}$ [3]) already indicated a small lead content. The refinement of the $\mathrm{Sn} / \mathrm{Pb}$ ratio of the $M(2)$ position $\left(R_{\mathrm{P}}=0.0611, w R_{\mathrm{P}}=0.0876\right)$ resulted in $28(1) \%$ lead for this site and an overall composition of $\mathrm{SrPb}_{0.42} \mathrm{Sn}_{2.58}$, which is in good agreement with the weighed sample composition.

For the Rietveld refinement of the structure of the phase obtained from the sample $\mathrm{SrPb}_{0.95} \mathrm{Sn}_{2.05}$ (6p), the model of the $\mathrm{PuAl}_{3}$-type, which allowed the full indexing of the powder pattern, was used. The lattice parameters converged at $a=701.06(1)$ and $c=1683.29(5) \mathrm{pm}\left(V /\right.$ f.u. $=119.4 \times 10^{6} \mathrm{pm}^{3}$; $R_{\mathrm{P}}=0.0212, w R_{\mathrm{P}}=0.0270$ and $\left.R_{F^{2}}=0.0580\right)$. The statistical Sn:Pb ratio of the $M(2)$ position could be refined to 38(1):62(1)\%, which is slightly Pb-richer than the relation of the single crystal refinements of $6\left(\mathrm{SrSn}_{2.05} \mathrm{~Pb}_{0.95}\right)$. Accordingly, the lattice parameters are somewhat increased.

\subsection{Band Structure Calculations}

DFT calculations of the electronic band structure were performed for the border phases of the compound series, $\mathrm{BaSn}_{3}$ and $\mathrm{SrPb}_{3}$, as well as for the two polymorphs of $\mathrm{BaPb}_{3}$ and for $\mathrm{SrSn}_{3}$ using the FP-LAPW method (programs WIEN2K [29] and ELK [30], cf. Table 4). Herein, the exchange-correlation contribution was described by the Generalized Gradient Approximation (GGA) of Perdew, Burke and Ernzerhof [31]. Muffin-tin radii were chosen as $121.7 \mathrm{pm}$ (2.3 a.u.) for all atoms. Cutoff energies used are $E_{\max }^{\text {pot }}=190 \mathrm{eV}$ (potential) and $E_{\max }^{\mathrm{wf}}=170 \mathrm{eV}$ (interstitial PW). Further parameters (e.g., number of $k$ points) and selected results of the calculations are collected in Table 4. Electron densities, the electron localisation function (ELF) [32,33] and Fermi surfaces were visualized using the programs XCRYSDEN [34] and DRAWXTL [35]. A Bader 'atoms in molecules' (AIM) analysis of the electron density map was performed to evaluate the charge distribution between the atoms and the heights and positions of the bond, ring and cage critical points [36] using the program CRITIC2 [37,38]. The total DOS (tDOS) plots of all compounds are discussed in Section 3.5.2. For the two border compounds of the series, $\mathrm{BaSn}_{3}$ and $\mathrm{SrPb}_{3}$, plots of the partial DOS (pDOS) and the band structures themselves are already reported elsewhere [3,10,11,14]. Maps of the ELF of $\mathrm{SrSn}_{3}$ based on LMTO-ASA calculations by Fässler et al. [3] are in very good agreement with the ELF obtained herein.

Both the band structures and the ELF of the binary compounds reported in the literature are considered in the discussion on the chemical bonding in Section 3.5.2. 
Table 4. Details of the calculation of the electronic structures of $\mathrm{BaSn}_{3}, \mathrm{BaPb}_{3}\left(\mathrm{BaPb}_{3}\right.$ - and $\mathrm{Mg}_{3} \mathrm{In}$-type), $\mathrm{SrSn}_{3}$ and $\mathrm{SrPb}_{3}$. ( $r_{\mathrm{MT}}$ : Muffin tin radius; $K_{\text {max }}$ : maximal wavevector for the $\mathrm{PW}$ in the interstitium; BCP: bond critical point; RCP: ring critical point; IBZ: irreducible part of the Brillouin zone; $V_{\mathrm{BB}}$ : volume of the Bader basins).

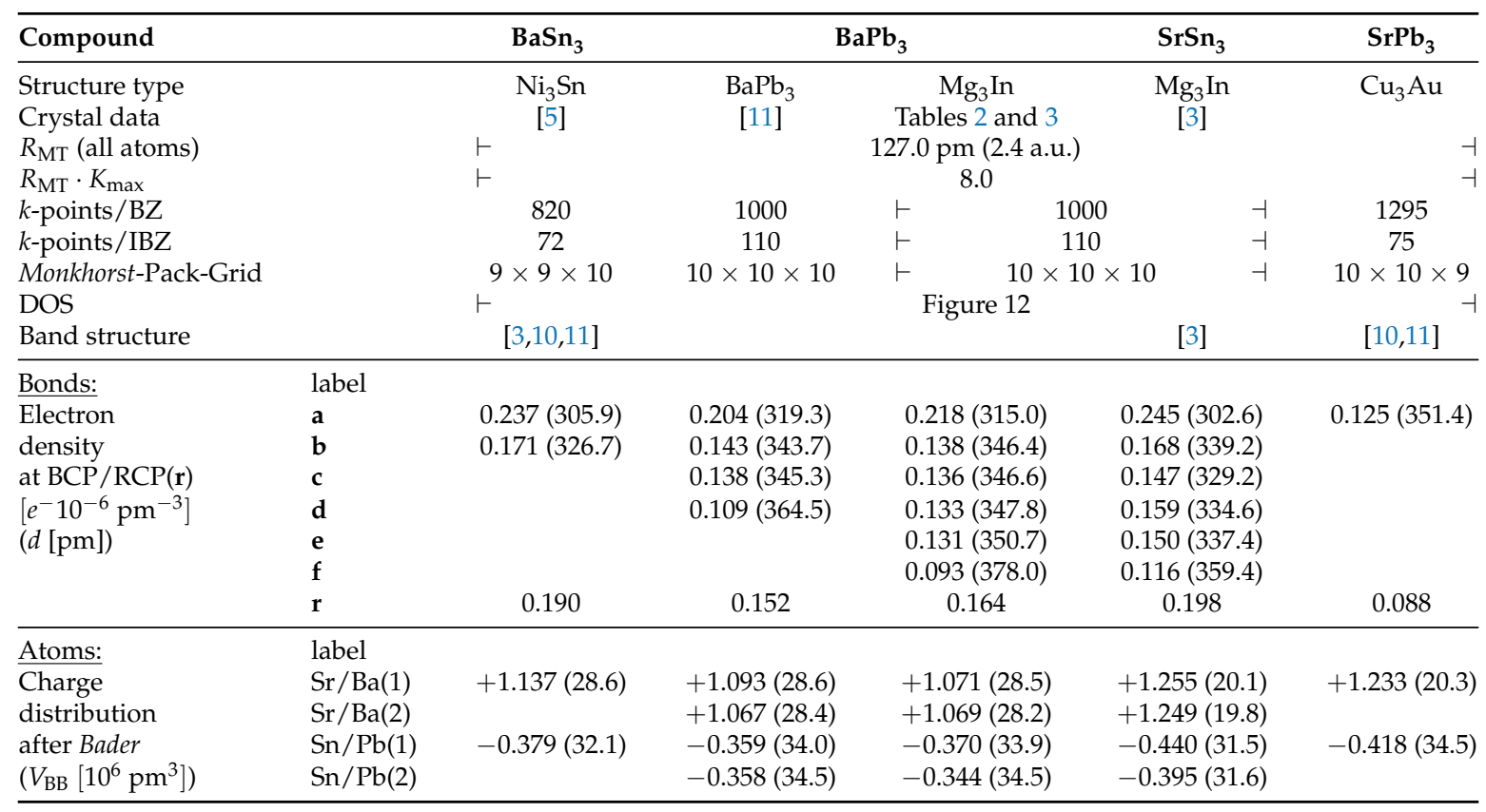

\section{Results and Discussion}

\subsection{Description of the Crystal Structures and Their Respective Phase Widths}

The structures of all tri-tetrelides exhibit hexagonal close packed ordered $A M_{3}$ layers containing $M$ kagomé (3.6.3.6.) nets. Depending on the stacking sequence, the $M$ polyanion resembles the oxygen substructure of the hexagonal [face-sharing octahedra, $|: \mathrm{AB}:| \equiv h$ stacking, $\mathrm{Ni}_{3} \mathrm{Sn}$-type, border compound $\mathrm{BaSn}_{3}$, Figure 1a] or the cubic [corner-sharing octahedra, $|: \mathrm{ABC}:| \equiv c$ stacking, $\mathrm{Cu}_{3} \mathrm{Au}$-type, border phase $\mathrm{SrPb}_{3}$, Figure 1f] perovskite. In between these border phases, a series of structures occur, in which the amount of cubic stacking increases continuously and simultaneously the size of the blocks of face-sharing octahedra decreases.

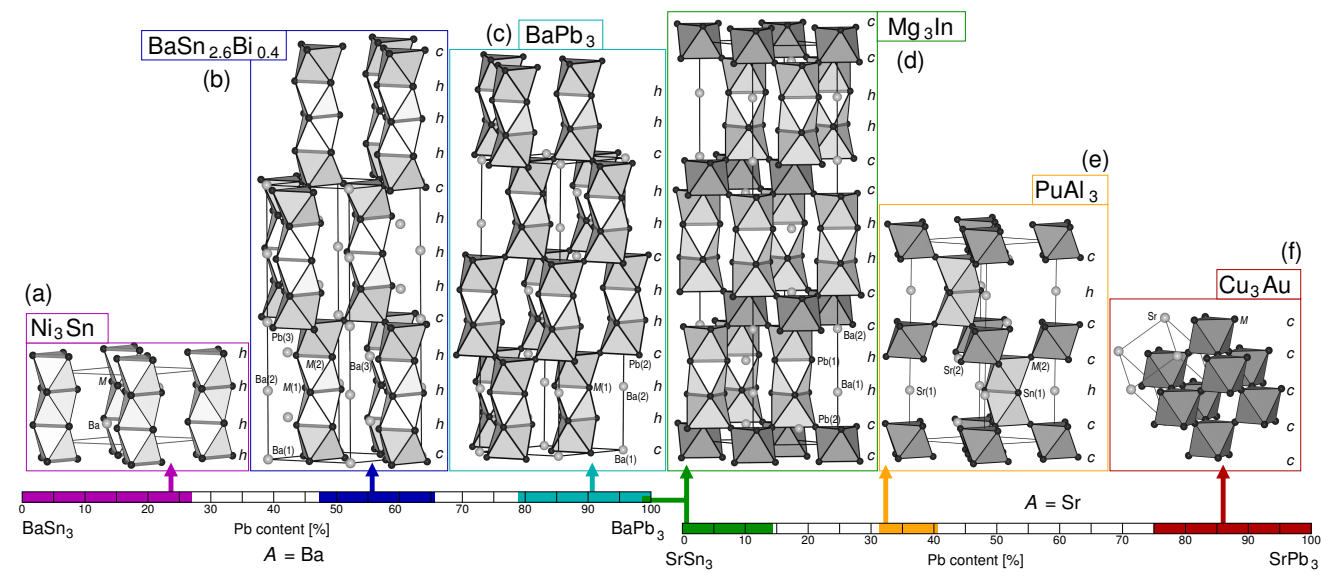

Figure 1. Crystal structures and phase widths (coloured bars) of the different stacking sequences observed in barium (left) and strontium (right) tri-stannides/plumbides (cf. the Figures 2-7 for enlarged views supplemented by the labeling of interatomic distances). 


\subsection{1. $\mathrm{Ni}_{3} \mathrm{Sn}$-Type Compounds}

In the long-known binary stannide $\mathrm{BaSn}_{3}[4,5]$, which forms the hexagonal $\mathrm{Ni}_{3} \mathrm{Sn}$-type ( $h P 8$, $P 6_{3} / m m c$ ), up to $28 \%$ of the $\mathrm{Sn}$ atoms can be substituted against $\mathrm{Pb}$ (magenta bar in Figure 1). The crystal structure of the lead-richest phase $\mathrm{BaSn}_{2.16} \mathrm{~Pb}_{0.84}(\mathbf{1})$ is depicted in Figure 2 in a polyhedra representation. The interatomic distances of this mixed stannide/plumbide are collected in Table 5 . The pure $h$ stacking of the hexagonal planar layers $\left[\mathrm{BaM}_{3}\right]$ results in infinite columns of $\left[M_{6 / 2}\right]$ octahedra sharing two opposite faces, which are running along the $c$ axis.

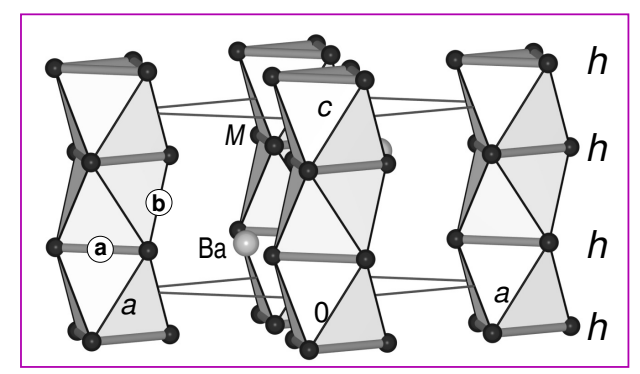

Figure 2. Crystal structure of $\mathrm{BaSn}_{2.16} \mathrm{~Pb}_{0.84}, \mathbf{1}\left(\mathrm{Ni}_{3} \mathrm{Sn}\right.$-type; bond distances cf. Table 5 [35]).

Table 5. Selected interatomic distances ( $\mathrm{pm})$ in the crystal structure of $\mathrm{BaSn}_{2.16} \mathrm{~Pb}_{0.84}, \mathbf{1}\left(\mathrm{Ni}_{3} \mathrm{Sn}\right.$-type). (cf. Figure 2 for the distance labels).

\begin{tabular}{|c|c|c|c|c|c|c|c|c|c|c|}
\hline \multicolumn{2}{|c|}{ Atoms } & \multirow{2}{*}{$\begin{array}{r}\text { Distance } \\
364.2(1)\end{array}$} & \multirow{2}{*}{$\begin{array}{r}\text { freq. } \\
6 \times\end{array}$} & \multirow[t]{2}{*}{$\mathrm{CN}$} & \multicolumn{2}{|c|}{ Atoms } & \multirow{2}{*}{$\begin{array}{r}\text { Distance } \\
313.6(2)\end{array}$} & \multirow{2}{*}{$\begin{array}{r}1 \mathrm{bl} . \\
\mathrm{a}\end{array}$} & \multirow{2}{*}{$\frac{\text { freq. }}{2 \times}$} & \multirow[t]{2}{*}{$\mathrm{CN}$} \\
\hline $\mathrm{Ba}$ & $-M$ & & & & $M$ & $-M$ & & & & \\
\hline & $-M$ & $366.3(1)$ & $6 \times$ & 12 & & $-M$ & $332.0(1)$ & b & $4 \times$ & \\
\hline & & & & & & $-\mathrm{Ba}$ & $364.2(1)$ & & $2 \times$ & \\
\hline & & & & & & $-\mathrm{Ba}$ & $366.3(1)$ & & $2 \times$ & 10 \\
\hline & & & & & & $-M$ & $412.6(2)$ & & $2 x$ & +2 \\
\hline
\end{tabular}

$\left[M_{3}\right]$ three-membered rings with short $M-M$ bonds of length $313.6 \mathrm{pm}$ (label a) form the common faces of the $\left[M_{6}\right]$ octahedra of the columns. The remaining octahedra edges are with $332.0 \mathrm{pm}(\mathbf{b})$ significantly larger. In the planar $M$ kagomé (3.6.3.6.) nets of the $\left[\mathrm{Ba}_{3}\right]$ hexagonal layers, the two remaining $M-M$ contacts are strongly elongated and lie with a distance of 412.6 pm clearly outside any bonding range. Thus, the $\left[M_{3}\right]$ triangles of the 3.6.3.6. net are alternatingly compressed and expanded. Therewith, the $M$ coordination is reduced from the anticuboctahedral 12 ( $8 M$ and $4 \mathrm{Ba}$ ) surrounding in the ideal hexagonal close packing to an overall $10(6+4)$ coordination. Compared to the binary border phase $\mathrm{BaSn}_{3}$ [4], the $M-M$ bond lengths (e.g., $d_{\mathrm{Sn}-\mathrm{Sn}}^{\mathrm{a}}=305.3 \mathrm{pm}$ ) and the unit cell volume (cf. discussion in Section 3.3) are increased as expected. The barium cations are coordinated by $12 \mathrm{Sn} / \mathrm{Pb}$ atoms in a next to regular anticuboctahedral fashion, with Ba-M distances of 364.2 and $366.3 \mathrm{pm}$.

\subsection{2. $\mathrm{BaSn}_{2.6} \mathrm{Bi}_{0.4}$-Type Compounds}

An increased lead content of 47 to $66 \%$ (dark blue bar in Figure 1) causes the formation of the hexagonal $\mathrm{BaSn}_{2.6} \mathrm{Bi}_{0.4}$-type (hP32, $P 6_{3} / m m c$, [18]) with a $(h h h c)_{2}$ stacking and blocks of four face-sharing octahedra (Figure 3). Selected interatomic distances of both border phases of this type, $\mathrm{BaSn}_{1.58} \mathrm{~Pb}_{1.42}$ (2) and $\mathrm{BaSn}_{1.01} \mathrm{~Pb}_{1.99}(3)$, are collected in Table 6 .

The structure type contains both three crystallographically different barium and three $M$ sites (Table 3). The latter are unequally taken by $\mathrm{Sn}$ and $\mathrm{Pb}$ : The $M(3)$ position, which forms the $\left[\mathrm{Ba}(1) \mathrm{Pb}(3)_{3}\right]$ layers of the $c$ stacking is occupied by lead exclusively. Reversely, the $M(1)$ position of a $h$ stacked layer with pure $h$ neighbor layers shows the lowest lead content (9.5-23.7\%). The intermediate $M(2)$ position of the hexagonal stacked [BaM(2) ${ }_{3}$ ] layer with an adjacent $h$ and $c$ layer contains an intermediate amount of lead (40.1-70.6\%). According to the stacking, the $M(1)$ and $M(2)$ atoms of 
the $h$ layers show a $6+4$ coordination and form kagomé nets with two different triangles, whereas the lead atoms $\mathrm{Pb}(3)$ exhibit the ideal $8+4$ surrounding and form an ideal 3.6.3.6. net among each other. The $\left[M(1)_{3}\right]$ three-membered rings forming the common faces between face-sharing octahedra contain the shortest $M-M$ bonds within the structure $\left(d^{\mathrm{a}}=302.8-306.3 \mathrm{pm}\right)$, whereas the analogous $\left[M(2)_{3}\right]$ ring is enlarged due to the increased Pb proportion $\left(d^{\mathfrak{c}}=313.3-318.5 \mathrm{pm}\right)$. All Ba cations are coordinated by $12 \mathrm{M}$ atoms in a cuboctahedral $[\mathrm{Ba}(1)$ and $\mathrm{Ba}(3)]$ or anticuboctahedral $[\mathrm{Ba}(2)]$ manner. The $\mathrm{Ba}-M$ distances are all lying in the narrow range 363.4 to $369.4 \mathrm{pm}$.

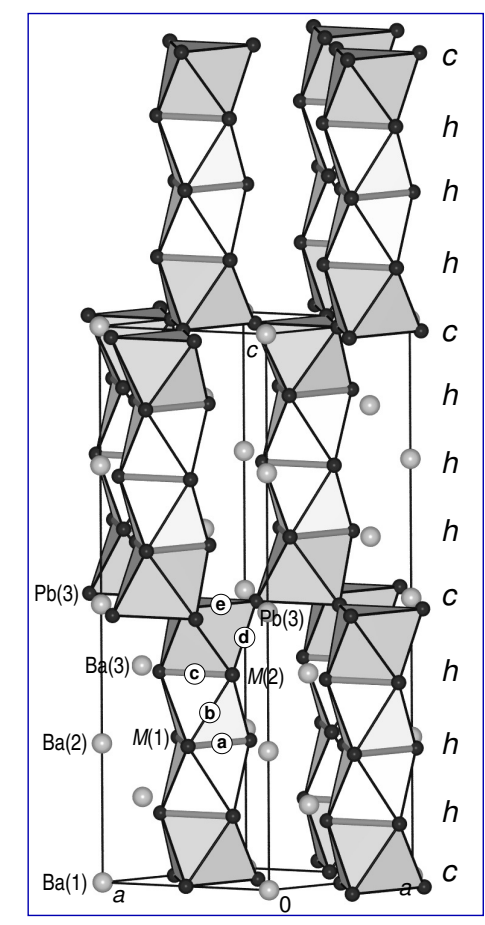

Figure 3. Crystal structure of $\mathrm{BaSn}_{1.58} \mathrm{~Pb}_{1.42}, 2\left(\mathrm{BaSn}_{2.6} \mathrm{Bi}_{0.4}\right.$-type; bond distances cf. Table 6 [35]).

Table 6. Selected interatomic distances (pm) in the crystal structures of the two border compounds $\mathrm{BaSn}_{1.58} \mathrm{~Pb}_{1.42}$ (2) and $\mathrm{BaSn}_{1.01} \mathrm{~Pb}_{1.99}$ (3) of the $\mathrm{BaSn}_{2.6} \mathrm{Bi}_{0.4}$-type (cf. Figure 3 for the distance labels).

\begin{tabular}{|c|c|c|c|c|c|c|c|c|c|c|c|c|}
\hline \multicolumn{2}{|c|}{ Atoms } & \multicolumn{2}{|c|}{ Distances in } & \multirow[t]{2}{*}{ freq. } & \multirow[t]{2}{*}{$\mathrm{CN}$} & \multicolumn{2}{|c|}{ Atoms } & \multicolumn{2}{|c|}{ Distances in } & \multirow[t]{2}{*}{ lbl. } & \multirow[t]{2}{*}{ freq. } & \multirow[t]{2}{*}{$\mathrm{CN}$} \\
\hline & & 2 & 3 & & & & & 2 & 3 & & & \\
\hline $\mathrm{Ba}(1)$ & $\begin{array}{l}-\mathrm{Pb}(3) \\
-M(2)\end{array}$ & $\begin{array}{l}363.4(1) \\
366.6(1)\end{array}$ & $\begin{array}{l}364.1(1) \\
366.5(1)\end{array}$ & $\begin{array}{l}6 \times \\
6 \times\end{array}$ & 12 & $M(1)$ & $\begin{array}{l}-M(1) \\
-M(2) \\
-\mathrm{Ba}(3) \\
-\mathrm{Ba}(2)\end{array}$ & $\begin{array}{l}302.8(3) \\
332.4(1) \\
354.5(2) \\
365.1(1)\end{array}$ & $\begin{array}{l}306.3(2) \\
336.2(1) \\
356.3(1) \\
365.6(1)\end{array}$ & $\begin{array}{l}a \\
b\end{array}$ & $\begin{array}{l}2 \times \\
4 \times \\
2 \times \\
2 \times\end{array}$ & $6+4$ \\
\hline $\mathrm{Ba}(2)$ & $\begin{array}{l}-M(1) \\
-M(2)\end{array}$ & $\begin{array}{l}365.1(1) \\
368.5(1)\end{array}$ & $\begin{array}{l}365.6(2) \\
369.4(1)\end{array}$ & $\begin{array}{l}6 \times \\
6 \times\end{array}$ & 12 & $M(2)$ & $\begin{array}{l}-M(2) \\
-M(1)\end{array}$ & $\begin{array}{l}313.3(2) \\
332.4(1)\end{array}$ & $\begin{array}{l}318.5(1) \\
336.2(1)\end{array}$ & $\begin{array}{l}\text { c } \\
\text { b }\end{array}$ & $\begin{array}{l}2 \times \\
2 \times\end{array}$ & \\
\hline $\mathrm{Ba}(3)$ & $\begin{array}{l}-M(1) \\
-M(2) \\
-P b(3)\end{array}$ & $\begin{array}{l}354.5(2) \\
365.4(1) \\
368.2(2)\end{array}$ & $\begin{array}{l}356.3(1) \\
365.8(1) \\
369.3(1)\end{array}$ & $\begin{array}{l}3 \times \\
6 \times \\
3 \times\end{array}$ & 12 & & $\begin{array}{l}-\mathrm{Pb}(3) \\
-\mathrm{Ba}(3) \\
-\mathrm{Ba}(1) \\
-\mathrm{Ba}(2)\end{array}$ & $\begin{array}{l}340.9(1) \\
365.4(1) \\
366.6(1) \\
368.5(1)\end{array}$ & $\begin{array}{l}343.1(1) \\
365.8(1) \\
366.5(1) \\
369.4(1)\end{array}$ & d & $\begin{array}{l}2 \times \\
2 \times\end{array}$ & $6+4$ \\
\hline & & & & & & $\mathrm{Pb}(3)$ & $\begin{array}{l}-M(2) \\
-\mathrm{Pb}(3) \\
-\mathrm{Ba}(1) \\
-\mathrm{Ba}(3)\end{array}$ & $\begin{array}{l}340.9(1) \\
363.4(1) \\
363.4(1) \\
368.2(2)\end{array}$ & $\begin{array}{l}343.1(1) \\
364.1(1) \\
364.1(1) \\
369.3(1)\end{array}$ & $\begin{array}{l}\text { d } \\
\text { e }\end{array}$ & $\begin{array}{l}4 \times \\
4 \times \\
2 \times \\
2 \times\end{array}$ & $8+4$ \\
\hline
\end{tabular}




\subsection{3. $\mathrm{BaPb}_{3}$-Type Compounds}

The stability range of the rhombohedral $\mathrm{BaPb}_{3}$-type sequence $(h h c)_{3}(h R 36, R \overline{3} m$, Figure 4$)$ starts at a lead proportion of $78 \%$ and reaches up to the pure plumbide $\mathrm{BaPb}_{3}$ [9] (cyan bar in Figure 1). This structure type, which should be termed $\mathrm{BaPb}_{3}$-type in consideration of the first structure determination in 1964 [9], is sometimes also denoted as $\mathrm{TaCo}_{3}$-type. The interatomic distances of the Sn-richest border phase $\mathrm{BaSn}_{0.65} \mathrm{~Pb}_{2.35}(4)$ are summarized in Table 7 .

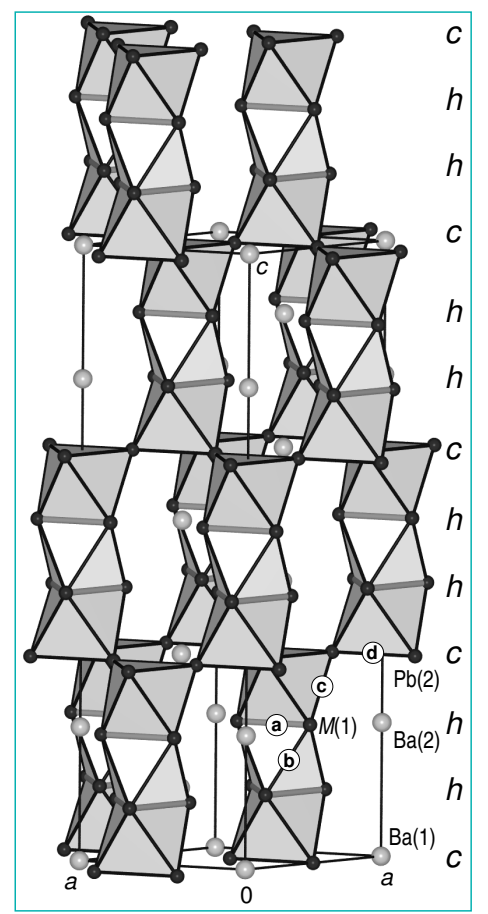

Figure 4. Crystal structure of $\mathrm{BaSn}_{0.65} \mathrm{~Pb}_{2.35}, 4\left(\mathrm{BaPb}_{3}\right.$-type; bond distances cf. Table 7 [35]).

Table 7. Selected interatomic distances (pm) in the crystal structure of $\mathrm{BaSn}_{0.65} \mathrm{~Pb}_{2.35}$ (4) forming the $\mathrm{BaPb}_{3}$-type (cf. Figure 4 for the distance labels).

\begin{tabular}{|c|c|c|c|c|c|c|c|c|c|c|}
\hline \multicolumn{2}{|c|}{ Atoms } & \multirow{2}{*}{$\begin{array}{r}\text { Distance } \\
360.0(2)\end{array}$} & \multirow{2}{*}{$\frac{\text { freq. }}{3 \times}$} & \multirow[t]{2}{*}{$\mathrm{CN}$} & \multicolumn{2}{|c|}{ Atoms } & \multirow{2}{*}{$\begin{array}{r}\text { Distance } \\
314.2(3)\end{array}$} & \multirow{2}{*}{$\frac{\mathrm{lbl} .}{\mathrm{a}}$} & \multirow{2}{*}{$\frac{\text { freq. }}{2 \times}$} & \multirow[t]{2}{*}{$\mathrm{CN}$} \\
\hline $\mathrm{Ba}(1)$ & $-M(1)$ & & & & $M(1)$ & $-M(1)$ & & & & \\
\hline & $-\mathrm{Pb}(2)$ & $364.8(2)$ & $3 \times$ & & & $-M(1)$ & $339.5(2)$ & b & $2 \times$ & \\
\hline & $-M(1)$ & $366.0(1)$ & $6 \times$ & 12 & & $-\mathrm{Pb}(2)$ & $342.6(1)$ & c & $2 \times$ & \\
\hline & & & & & & $-\mathrm{Ba}(1)$ & $360.0(2)$ & & & \\
\hline \multirow[t]{6}{*}{$\mathrm{Ba}(2)$} & $-\mathrm{Pb}(2)$ & $364.4(1)$ & $6 \times$ & & & $-\mathrm{Ba}(1)$ & $366.0(1)$ & & $2 \times$ & \\
\hline & $-M(1)$ & 368.3(1) & $6 \times$ & 12 & & $-\mathrm{Ba}(2)$ & 368.3(1) & & & $6+4$ \\
\hline & & & & & $\mathrm{Pb}(2)$ & $-M(1)$ & $342.6(1)$ & c & $4 \times$ & \\
\hline & & & & & & $-\mathrm{Pb}(2)$ & $364.4(1)$ & d & $4 \times$ & \\
\hline & & & & & & $-\mathrm{Ba}(2)$ & $364.4(1)$ & & $2 \times$ & \\
\hline & & & & & & $-\mathrm{Ba}(1)$ & $364.8(2)$ & & $2 \times$ & $8+4$ \\
\hline
\end{tabular}

In the lead-rich compounds of the Ba series, the planar nets $\left[\mathrm{Ba}_{3}\right]$ follow the rhombohedral $(h h c)_{3}$ stacking sequence and the blocks of face-sharing octahedra are now consisting of three octahedra only (Figure 4 ). Within these trimers, the $\left[M_{6}\right]$ octahedra share common triangular faces $\left[M(1)_{3}\right]$ with the shortest interatomic distances of the whole structure $\left(d^{\mathrm{a}}=314.2 \mathrm{pm}, \mathrm{cf}\right.$. Table 7$)$. As expected from the tin content, this and all further $M-M$ distances are somewhat shortened with respect to the isotypic pure plumbide (e.g., $d^{\mathbf{a}}=319.3 \mathrm{pm}$, [11]). The octahedra trimers are connected via the six corners formed by the pure lead position $[\mathrm{Pb}(2)]$. According to the point group symmetry $\cdot \frac{2}{m}$ of the 
$\mathrm{Pb}(2)$ position, these atoms form ideal kagomé nets at $z=0, \frac{1}{3}$ and $\frac{2}{3}$ in the unit cell. The mesh width of this net, i.e., the $\mathrm{Pb}(2)-\mathrm{Pb}(2)$ distances $(4 \times)$ are comparatively large $364.4 \mathrm{pm}$, whereas the remaining $M-M$ distances are of intermediate lengths (339.5 and $342.6 \mathrm{pm}$ ). Again, the atoms forming the $h$ layers exhibit a $6+4$ coordination, whereas the $c$ net position $[\mathrm{Pb}(2)]$ has the full $8 M+4$ Ba surrounding of a dense packing. The $\mathrm{Ba}(1)$ cations show a cuboctahedral, $\mathrm{Ba}(2)$ an anticuboctahedral, both fairly regular $\left(d_{\mathrm{Ba}-M}=360.0-368.3 \mathrm{pm}\right)$, twelvefold $M$ coordination.

\subsection{4. $\mathrm{Mg}_{3} \mathrm{In}$-Type Compounds}

A second new polymorph of $\mathrm{BaPb}_{3}$ (denoted $\mathrm{BaPb}_{3}-\mathrm{II}$ hereafter) crystallizes in the $\mathrm{Mg}_{3}$ In-type structure with a further increased amount of cubic sequences [ $(h h c c)_{3} ; h R 48$, Figure 5]. This form of $\mathrm{BaPb}_{3}$ is thus isotypic with the border phase $\mathrm{SrSn}_{3}$ [3] of the respective $\mathrm{Sr}$ series and with the lead-containing compounds up to a $\mathrm{Pb}$ content of $14 \%\left(\mathrm{SrSn}_{2.58} \mathrm{~Pb}_{0.42}, 5 \mathrm{p}\right.$; green bar in Figure 1$)$. The structure model of these compounds should be denoted $\mathrm{Mg}_{3}$ In-type, because the crystallographic data of this particular compound were the first one published in 1963 [28]. Two years later, an isotypic structure was reported for the high-temperature form of $\mathrm{PuGa}_{3}$ and only much later (2000, [3]) the tri-stannide $\mathrm{SrSn}_{3}$ was added. The two latter compounds are nevertheless widely (e.g., in the Inorganic Crystal Structure Database [39]) used to address this structure type.

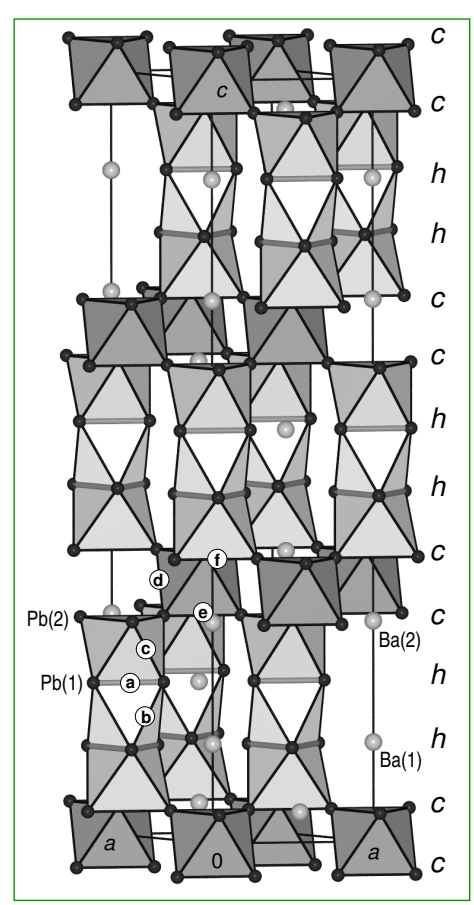

Figure 5. Crystal structure of $\mathrm{BaPb}_{3}-\mathrm{II}, 5$ ( $\mathrm{Mg}_{3}$ In-type; bond distances cf. Table 8 [35]).

In the structure of $\mathrm{BaPb}_{3}$-II (Figure 5) the rhombohedral stacking sequence $(\text { hhcc })_{3}$ results in octahedra trimers, which are not directly connected via corners as in $\mathrm{BaPb}_{3}-\mathrm{I}$, but an additional layer of corner-connected $\left[\mathrm{Pb}(2)_{6}\right]$ octahedra is interspersed. Overall, a 1:1 relation of $h$ and $c$ layers, i.e., $\mathrm{Pb}(1)$ and $\mathrm{Pb}(2)$ atoms, are reached. In addition, in this case, the $\mathrm{Pb}-\mathrm{Pb}$ distances of the common $\left[\mathrm{Pb}(1)_{3}\right]$ triangles of the face-sharing lead octahedra are with $315.0 \mathrm{pm}$ the shortest bonds within the structure. All other $\mathrm{Pb}-\mathrm{Pb}$ distances are found in the range $346-378 \mathrm{pm}$, whereby the largest values are again in the $c$-stacked kagomé nets $[\mathrm{Pb}(2)-\mathrm{Pb}(2)]$. In contrast to the $c$ layers in the $\mathrm{BaPb}_{3}$-type structures, the 3.6.3.6. $\mathrm{Pb}(2)$ nets exhibit two different triangles with $\mathrm{Pb}(2)-\mathrm{Pb}(2)$ edges of 350.7 and $378.0 \mathrm{pm}$. Nevertheless, the $\left[\mathrm{Pb}(2)_{3}\right]$ triangles in the $h$ layers are much more different in size $(315.0 / 413.7 \mathrm{pm})$. Due to these compressed/expanded triangles, the $\mathrm{Pb}(1)$ atoms of the common octahedra faces are surrounded by 6 $\mathrm{Pb}$ and $4 \mathrm{Ba}$ cations only, whereas $\mathrm{Pb}(2)$ of the $c$ net exhibits the complete 12-fold coordination, even 
though two lead neighbors are already at a slightly larger distance than the four Ba cations (Table 8). The cations themselves again show the ideal 12 -fold lead coordination, with 50\% cuboctahedral [Ba(2)] and $50 \%$ anticuboctahedral $[\mathrm{Ba}(1)]$ arrangement. The $\mathrm{Mg}_{3}$ In-type structure has been already observed (and predicted by van Vucht in 1966 [7]) for pure plumbides with a small substitution of barium by calcium or strontium (for $A_{x} \mathrm{Ba}_{1-x} \mathrm{~Pb}_{3}: x=0.03$ for $\mathrm{Ca}$ and 0.10 for $\mathrm{Sr}$ [11]). It also occurs in the compound series $\mathrm{Ba}\left(\mathrm{Sn}_{x} \mathrm{Bi}_{1-x}\right)_{3}$ [18] and from $\mathrm{SrSn}_{3}$ to $\mathrm{SrSn}_{2.58} \mathrm{~Pb}_{0.42}$ (5p). Unfortunately (due to problems with the crystal quality in the Sr series, cf. Section 2.2) the structure of the latter compound has been refined from powder data only (Section 2.3). As expected, the lattice parameters and all $M-M$ bonds are slightly elongated compared to $\mathrm{SrSn}_{3}$ and the lead atoms are substituted at the $c$ stacked layers, i.e., the $M(2)$ position.

Table 8. Selected interatomic distances ( $\mathrm{pm})$ in the crystal structure of $\mathrm{BaPb}_{3}\left(\mathrm{Mg}_{3}\right.$ In-type structure). (cf. Figure 5 for the distance labels).

\begin{tabular}{|c|c|c|c|c|c|c|c|c|c|c|}
\hline \multicolumn{2}{|c|}{ Atoms } & \multirow{2}{*}{$\begin{array}{r}\text { Distance } \\
361.7(2)\end{array}$} & \multirow{2}{*}{$\begin{array}{c}\text { freq. } \\
3 \times\end{array}$} & \multirow[t]{2}{*}{$\mathrm{CN}$} & \multicolumn{2}{|c|}{ Atoms } & \multirow{2}{*}{$\begin{array}{r}\text { Distance } \\
315.0(2)\end{array}$} & \multirow{2}{*}{$\frac{1 b l .}{a}$} & \multirow{2}{*}{$\frac{\text { freq. }}{2 \times}$} & \multirow[t]{2}{*}{$\mathrm{CN}$} \\
\hline $\mathrm{Ba}(1)$ & $-\mathrm{Pb}(1)$ & & & & $\mathrm{Pb}(1)$ & $-\mathrm{Pb}(1)$ & & & & \\
\hline & $-\mathrm{Pb}(2)$ & $365.6(2)$ & $3 \times$ & & & $-\mathrm{Pb}(1)$ & $346.4(2)$ & b & $2 \times$ & \\
\hline & $-\mathrm{Pb}(1)$ & $366.2(1)$ & $6 \times$ & 12 & & $-\mathrm{Pb}(2)$ & $346.6(1)$ & c & $2 \times$ & \\
\hline & & & & & & $-\mathrm{Ba}(2)$ & $361.6(2)$ & & & \\
\hline \multirow[t]{10}{*}{$\mathrm{Ba}(2)$} & $-\mathrm{Pb}(1)$ & $361.6(2)$ & $3 x$ & & & $-\mathrm{Ba}(1)$ & $361.7(2)$ & & & \\
\hline & $-\mathrm{Pb}(2)$ & $364.6(1)$ & $6 \times$ & & & $-\mathrm{Ba}(1)$ & $366.2(1)$ & & $2 \times$ & $6+4$ \\
\hline & $-\mathrm{Pb}(2)$ & $365.0(2)$ & $3 \times$ & 12 & & & & & & \\
\hline & & & & & $\mathrm{Pb}(2)$ & $-\mathrm{Pb}(1)$ & $346.6(1)$ & c & $2 \times$ & \\
\hline & & & & & & $-\mathrm{Pb}(2)$ & $347.8(2)$ & d & $2 \times$ & \\
\hline & & & & & & $-\mathrm{Pb}(2)$ & $350.7(2)$ & e & $2 \times$ & \\
\hline & & & & & & $-\mathrm{Ba}(2)$ & $364.6(1)$ & & $2 \times$ & \\
\hline & & & & & & $-\mathrm{Ba}(2)$ & $365.0(2)$ & & & \\
\hline & & & & & & $-\mathrm{Ba}(1)$ & $365.6(2)$ & & & \\
\hline & & & & & & $-\mathrm{Pb}(2)$ & $378.0(2)$ & $\mathbf{f}$ & $2 \times$ & $6+4+2$ \\
\hline
\end{tabular}

In the vast series of tri-metallides of the structure family considered, polymorphism (like the one observed herein for $\mathrm{BaPb}_{3}$ ) is very frequent. An instructive example are the tri-gallides of the rare earth elements, were the smaller $\mathrm{Er}$, $\mathrm{Tm}$ and $\mathrm{Lu}$ cations form $\mathrm{Cu}_{3} \mathrm{Au}$-type structures, whereas $\mathrm{Tb}$, Dy and Ho are di- or even trimorphic [40]. For the two modifications of $\mathrm{BaPb}_{3}$, the difference of the unit cell volumes per formula unit ( $V /$ f.u.) is even smaller than $0.1 \%$ [131.16 (I) compared to $131.07 \times 10^{6} \mathrm{pm}^{3}$ (II)] and an experimental hint towards the phase relation between the two polymorphs is also not obvious.

\subsection{5. $\mathrm{PuAl}_{3}$-Type Compounds}

In the $\mathrm{Sr}$ series, a $\mathrm{Pb}$ content of $32 \%\left(\mathrm{SrSn}_{2.05} \mathrm{~Pb}_{0.95}, 6\right)$ to $41 \%\left(\mathrm{SrSn}_{1.77} \mathrm{~Pb}_{1.23}, 6 \mathbf{p}\right)$ causes a small existence region of the hexagonal $\mathrm{PuAl}_{3}$-type $\left(h P 24, P 6_{3} / \mathrm{mmc}\right.$ [41]) with a $(h c c)_{2}$ stacking (golden bar in Figure 1). The structure and selected bond lengths are found in Figure 6 and Table 9.

The increased proportion of $c$ stacking in the $\mathrm{PuAl}_{3}$-type reduces the size of the blocks of face-sharing octahedra to dimers, which are separated by additional $c$ stacked $[M(2) 6]$ corner-sharing octahedra. Again, tin prefer the occupation of the $h$ layer and the shortest distances are found in the common face triangle inside this layer $\left(d_{\mathrm{Sn}(1)-\mathrm{Sn}(1)}^{\mathrm{a}}=302.9 \mathrm{pm}\right)$. The triangles of the $h$ net are thus of very different size, whereas the $M(2)$ kagomé nets of the $c$ layers are only slightly distorted (345.0, $\mathbf{d} / 352.0$, e pm). The overall coordination of the $h$ and $c$ layer $M$ atoms and the strontium cations again fits the situation throughout the whole structure family. 


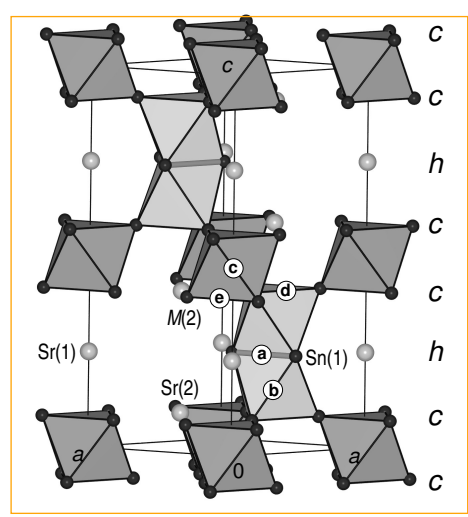

Figure 6. Crystal structure of $\mathrm{SrSn}_{2.05} \mathrm{~Pb}_{0.95}, 6$ ( $\mathrm{PuAl}_{3}$-type; bond distances cf. Table 9 [35]).

Table 9. Selected interatomic distances (pm) in the crystal structure of $\mathrm{SrSn}_{2.05} \mathrm{~Pb}_{0.95}\left(\mathrm{PuAl}_{3}\right.$-type). (cf. Figure 6 for the distance labels).

\begin{tabular}{|c|c|c|c|c|c|c|c|c|c|c|}
\hline \multicolumn{2}{|c|}{ Atoms } & \multirow{2}{*}{$\begin{array}{r}\text { Distance } \\
348.4(2)\end{array}$} & \multirow{2}{*}{$\frac{\text { freq. }}{6 \times}$} & \multirow[t]{2}{*}{$\mathrm{CN}$} & \multicolumn{2}{|c|}{ Atoms } & \multirow{2}{*}{$\begin{array}{r}\text { Distance } \\
302.9(8)\end{array}$} & \multirow{2}{*}{$\frac{\mathrm{lbl} .}{\mathrm{a}}$} & \multirow{2}{*}{$\frac{\text { freq. }}{2 \times}$} & \multirow[t]{2}{*}{$\mathrm{CN}$} \\
\hline $\operatorname{Sr}(1)$ & $-M(2)$ & & & & $\operatorname{Sn}(1)$ & $-\operatorname{Sn}(1)$ & & & & \\
\hline & $-S n(1)$ & $349.5(1)$ & $6 \times$ & 12 & & $-M(2)$ & $339.9(2)$ & b & $4 \times$ & \\
\hline & & & & & & $-\operatorname{Sr}(2)$ & $347.8(6)$ & & $2 \times$ & \\
\hline \multirow[t]{10}{*}{$\operatorname{Sr}(2)$} & $-\operatorname{Sn}(1)$ & $347.8(6)$ & $3 x$ & & & $-\operatorname{Sr}(1)$ & $349.5(1)$ & & $2 \times$ & $6+4$ \\
\hline & $-M(2)$ & 349.1(1) & $6 x$ & & & $-\operatorname{Sn}(1)$ & 394.1(8) & & $2 \times$ & \\
\hline & $-M(2)$ & $353.2(7)$ & $3 x$ & 12 & & & & & & \\
\hline & & & & & $M(2)$ & $-M(2)$ & $339.3(4)$ & c & $2 \times$ & \\
\hline & & & & & & $-\operatorname{Sn}(1)$ & $339.9(2)$ & b & $2 \times$ & \\
\hline & & & & & & $-M(2)$ & $345.0(4)$ & d & $2 \times$ & \\
\hline & & & & & & $-\operatorname{Sr}(1)$ & $348.4(2)$ & & & \\
\hline & & & & & & $-\operatorname{Sr}(2)$ & 349.1(1) & & $2 \times$ & \\
\hline & & & & & & $-M(2)$ & $352.0(4)$ & e & $2 \times$ & \\
\hline & & & & & & $-\operatorname{Sr}(2)$ & $353.2(7)$ & & & $8+4$ \\
\hline
\end{tabular}

\subsection{6. $\mathrm{Cu}_{3} \mathrm{Au}$-Type Compounds}

The strontium series is terminated by the pure $(c)_{3}$ stacking of $\mathrm{SrPb}_{3}\left(\mathrm{Cu}_{3} \mathrm{Au}\right.$-type, $\left.c P 4, P m \overline{3} m\right)$, which starts at a lead content of approximately $75 \%$. Because of problems with the single crystal quality, a reliable refinement of the $\mathrm{Sn} / \mathrm{Pb}$ occupation was not possible, so that some uncertainty of the exact composition remains. The very broad reflections of the powder diffraction pattern prohibit even a full-pattern Rietveld refinement and a decision is not possible, whether the tetragonal distortion of the cubic $\mathrm{Cu}_{3} \mathrm{Au}$-type, which is reported in the literature for the binary tri-plumbide $\mathrm{SrPb}_{3}$ [6], also arises in the ternary tin-containing phase.

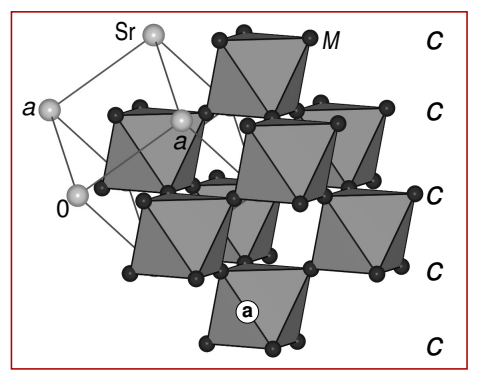

Figure 7. Crystal structure of $\mathrm{SrSn}_{0.75} \mathrm{~Pb}_{2.25}, 7\left(\mathrm{Cu}_{3} \mathrm{Au}\right.$-type; bond distances cf. Table 10 [35]).

In accordance with the presence of smaller $S n$ atoms, the lattice parameter and therewith the $M-M$ distance of $350.3 \mathrm{pm}$ is somewhat decreased compared to the two distances found in the tetragonal 
border phase $\mathrm{SrPb}_{3}\left(d_{\mathrm{Pb}-\mathrm{Pb}}=351.1,353.2 \mathrm{pm} \mathrm{[6]}\right)$. The structure terminates the series with a pure $c$ stacking and a polyanion, which consists of ideal corner-sharing $\left[M_{6 / 2}\right]$ octahedra. All atoms exhibit an ideal cuboctahedral surrounding with one unique distance of $350.3 \mathrm{pm}$ (cf. Table 10).

Table 10. Selected interatomic distances $(\mathrm{pm})$ in the crystal structure of $\mathrm{SrSn}_{0.75} \mathrm{~Pb}_{2.25}$ $\left(\mathrm{Cu}_{3} \mathrm{Au}\right.$-type structure).

\begin{tabular}{|c|c|c|c|c|c|c|c|c|c|c|}
\hline \multicolumn{2}{|c|}{ Atoms } & \multirow{2}{*}{$\begin{array}{r}\text { Distance } \\
350.3(1)\end{array}$} & \multirow{2}{*}{$\begin{array}{c}\text { freq. } \\
12 \times\end{array}$} & \multirow{2}{*}{$\frac{\mathrm{CN}}{12}$} & \multicolumn{2}{|c|}{ Atoms } & \multirow{2}{*}{$\begin{array}{r}\text { Distance } \\
350.3(1) \\
3503(1)\end{array}$} & \multirow{2}{*}{$\begin{array}{r}\text { lbl. } \\
a\end{array}$} & \multirow{2}{*}{$\begin{array}{r}\text { freq. } \\
6 \times \\
6 \times\end{array}$} & \multirow{2}{*}{$\begin{array}{l}\mathrm{CN} \\
6+6\end{array}$} \\
\hline $\mathrm{Sr}$ & $-M$ & & & & $M$ & $\begin{array}{l}-M \\
-S r\end{array}$ & & & & \\
\hline
\end{tabular}

\subsection{Stacking Sequences: Geometric Aspects}

The series of mixed $\mathrm{Sn} / \mathrm{Pb}$ tri-tetrelides discussed above, as well as similar systematic studies on mixed $\mathrm{Ca} / \mathrm{Sr} / \mathrm{Ba}$ stannides [10] and plumbides [11], clearly show, that the amount of $h / c$ stacking in the structure family of $\mathrm{AB}_{3}$ superstructures of dense sphere packing and hence the sequence of the different structure types is essentially determined by the radius ratio of the two elements. This becomes apparent from the coherent progress of the amount of hexagonal stacking with the radius ratio of the two elements shown in Figure 8. Similar plots are presented for a great variety of compounds in the literature $[7,8]$. In contrast to these works, in which metallic radii were used to estimate the atomic sizes, ionic radii (after Shannon [42], for $\mathrm{CN}=12$ ) were used herein to estimate the size of the $A$ cations, and metallic radii (after Gschneidner [43], for $\mathrm{CN}=12$ ) were only applied to quantify the size of the $\mathrm{Sn}$ and $\mathrm{Pb}$ atoms. This choice of radii is in agreement with the next to complete electron transfer from the alkaline-earth elements $A$ to $\mathrm{Sn} / \mathrm{Pb}$ (cf. Section 3.5.2). The diagram shown in Figure 8 demonstrates the direct relation between the stacking sequence and the radius ratio, independent of the type of the $M$ atom, i.e., both for $\mathrm{Sn}$ (squares and thin dashed line), $\mathrm{Pb}$ (circles and thin solid line) or $\mathrm{Sn}$ and $\mathrm{Pb}$ (with a distinct distribution at the $h / c$ layer, colored triangles and bold lines).

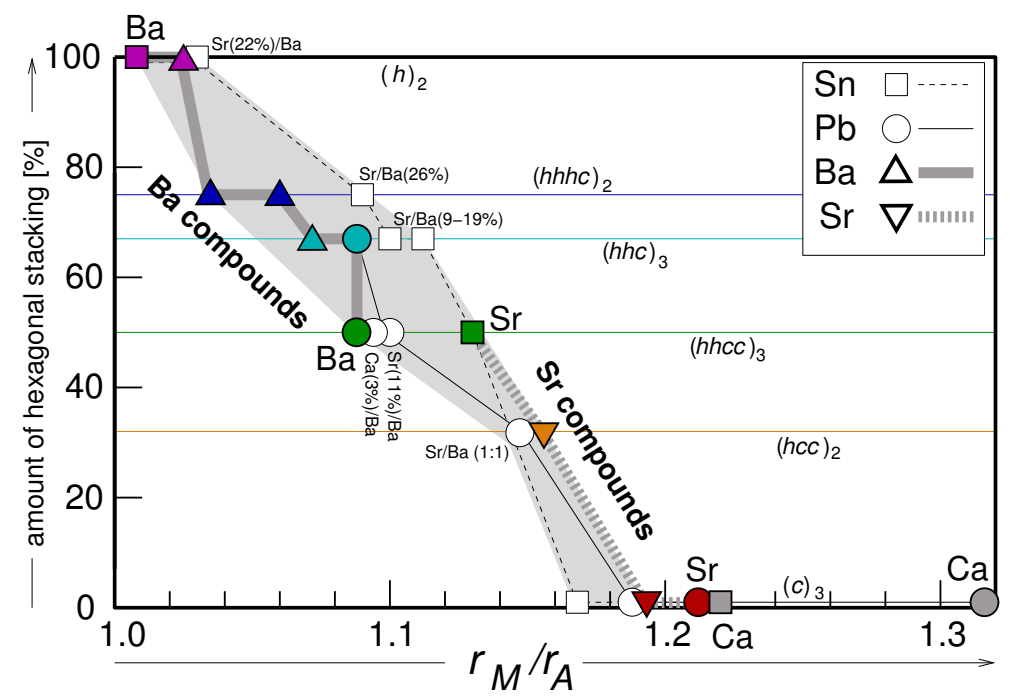

Figure 8. Amount of hexagonal stacking plotted versus the radius ratio $r_{M}: r_{A}$ in (mixed) alkaline-earth tri-stannides (thin squares and dashed line) and -plumbides (thin circles and line) and the mixed stannides/plumbides (triangles and bold gray lines) reported in this work.

This general behaviour can be explained by the decreased (10) coordination number of the atoms of the $h$ layers $(6 \times M+4 \times A)$ compared to the ideal twelvefold $(8 \times M+4 \times A)$ coordination of the $M$ atoms of $c$ stacked layers (Figure 9). 
However, the reason for the reduction of the coordination sphere of $h$-type atoms from 12 to 10 is the compression of the common $\left[M_{3}\right]$ triangle of two face-sharing octahedra, which is causally linked to covalent bonding contributions within the $M$ polyanion (cf. Section 3.5).

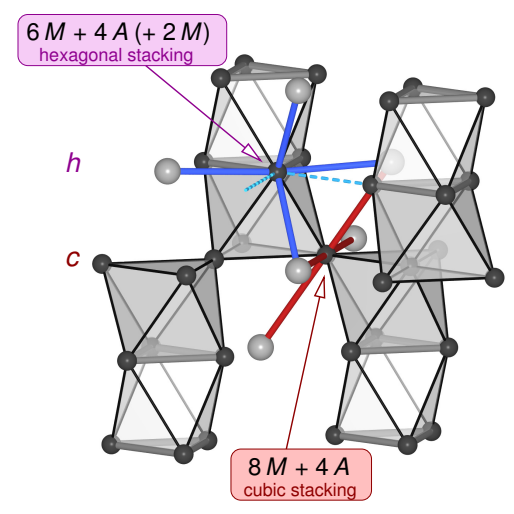

Figure 9. Comparison of the characteristic coordination spheres of $\mathrm{Sn} / \mathrm{Pb}$ atoms of a hexagonal (violet-blue) and a cubic (red) stacked layer [35].

In electron poorer compounds (like for example $\mathrm{CaHg}_{3}$ or $\mathrm{SrHg}_{3}$ [44]), which crystallize in the $\mathrm{Ni}_{3} \mathrm{Sn}$-type, the $M-M$ triangles do not show shortened edges/bonds (cf. also the discussion on the value of the atomic $x$ parameter in the $\mathrm{Ni}_{3} \mathrm{Sn}$ and related structures by Havinga in [8]).

\subsection{Molar Volumes and Variation of the $c / a$ Ratio}

Regardless of the different stacking sequences, the molar volumes of all tri-tetrelides follow Vegards rule (gray circles and thin black lines in Figure 10). The normalized interlayer distance, i.e., the $c / a$ ratio/two layers (open circles and gray lines) decreases continuously with (i) increasing $h$ stacking (thick gray lines) and (ii) with the Sn content of each distinct structure type. This increasing hexagonal unit cell basis is a consequence of the covalent bonding contributions and the stereochemically active lone electron pair (l.e.p., see Section 3.5) of the tin (and less pronounced the lead) atoms of the $h$ layers in the electron-richer compounds of the $\mathrm{AB}_{3}$ structure family. Simple packing/geometric arguments failed to explain this general trend, which is similarly observed for other electron-richer compounds of this structure family $[7,8]$.

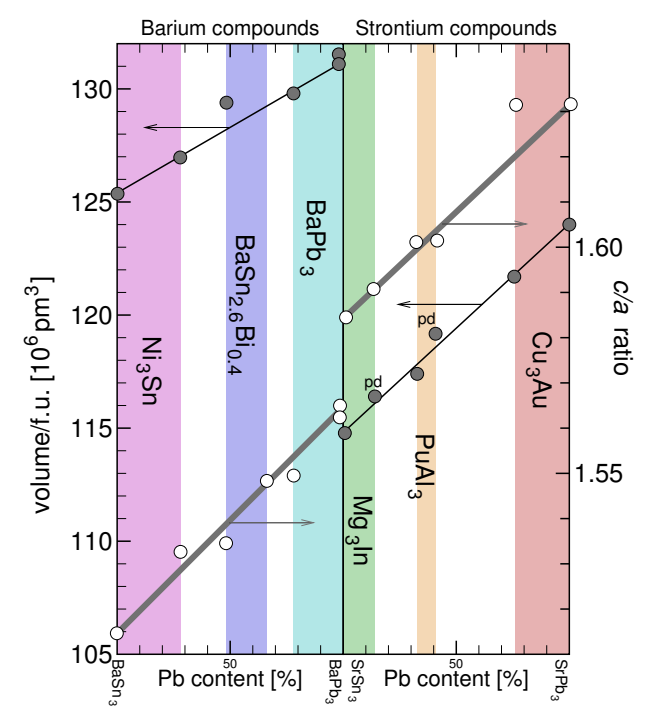

Figure 10. Normalized unit cell volumes $V /$ f.u. and $c / a$ ratios (for two layers) of the mixed tri-stannides/plumbides of barium (left) and strontium (right). 


\subsection{Sn/Pb Distribution: 'Coloring' Aspects}

Concerning the 'coloring' [19], i.e., the preference of tin and lead to occupy the differently stacked layers, the clear preference of Sn atoms to occupy the $h$ nets is valid throughout the whole family of the tri-tetrelides. Arguments for this very uniform coloring are at one hand the reduced coordination sphere of the $h$ layer atoms (cf. Section 3.2), which may better fit the smaller $M$ atom types. On the other hand, the larger $\mathrm{Sn}-\mathrm{Sn}$ (compared to $\mathrm{Pb}-\mathrm{Pb}$ ) single bond energies direct tin to take those sites in the structure, where generally the shortest bonds are formed; this is unequivocally the $h$ position.

\subsection{Chemical Bonding, Electronic Structure}

Calculations of the electronic band structure, based on different levels of theory, are already reported in vast detail for several border phases of the title compound series. The results of LMTO-ASA calculations of $\mathrm{SrSn}_{3}[3]$ and $\mathrm{BaSn}_{3}$ [5] are in very good agreement with the FP-LAPW results discussed in $[10,11]$. The obtained electron densities of these DFT calculations reveal the different types of Sn-Sn bonds as well as the presence of the 1.e.p. at the $h$-stacked tin atoms [10]. The related ELF exhibits comparatively low (approx. 0.6) maxima at the bonds of the common octahedra edges and for the 1.e.p. of $h$-type atoms [3]; whereas the ELF obtained from EH calculations shows significantly more pronounced features (e.g., [5] for $\mathrm{BaSn}_{3}$ ). The band structures of the cubic phases like $\mathrm{CaPb}_{3}$ and $\mathrm{SrPb}_{3}$ were also calculated using FP-LMTO [14] and FP-LAPW [10,11] methods. A detailed discussion of the band structure from the point of view of chemical bonding can be found in [10]. In this work, the literature's theoretical work is complemented by FP-LAPW calculations of the new polymorph of $\mathrm{BaPb}_{3}$, which-according to its isotypy to $\mathrm{SrSn}_{3}$-allows for a direct comparison of an $\mathrm{Sn}$ with an isotypic $\left(\mathrm{Mg}_{3} \mathrm{In}\right.$-type) $\mathrm{Pb}$ compound. Corresponding calculations of the border phases $\mathrm{BaSn}_{3}, \mathrm{BaPb}_{3}-\mathrm{I}$, $\mathrm{SrSn}_{3}$ and $\mathrm{BaPb}_{3}$ (Table 4) are also included for comparison and for a detailed analysis of the electron density. Independent of the stacking of the close-packed layers, the total density of states (tDOS) show pronounced minima next to the Fermi level (14 v.e./f.u.), which implies the validity of simple electron counting rules.

\subsubsection{Electron Count (Zintl/Wade/mno)}

Compounds with the pure $h$ stacking like e.g., $\mathrm{BaSn}_{3}$ exhibit three-membered rings with short $M-M$ bonds, which are only slightly larger than single bond distances, and the calculated electron density shows the highest electron density at the respective bond critical points $\left(\rho_{\mathrm{BCP}}=0.237 \mathrm{e}^{-} 10^{-6} \mathrm{pm}^{-3}\right.$, Table 4 and [10]). Neglecting all further $M-M$ contacts-as proposed in [5]-the compound contains Zintl anions $\left[M_{3}\right]^{2-}$ with an aromatic $\pi$ system of two electrons. Admittedly, the results of the band structure calculations [10] show, that this simplified model is only of limited applicability: No (pseudo) band gap can be found at the Fermi level (cf. Figure 12) and the number of $p_{z}$-type bands below $E_{\mathrm{F}}$ is not compatible with an aromatic $\pi$ system. However, the evident stability of the whole structure family at (or close to) 14 v.e. per formula unit (i.e., $4 \frac{2}{3}$ v.e. $/ M$ ) can be explained both for the $h$ and the $c$ stacking (and therewith also for all stacking variants in between) when taking the 'polyaromatic' bonding character (cf. the longer $M-M$ bonds and the ring critical points, Section 3.5.2) into account and extending the Zintl concept by Wade's electron counting rules [45] or the somewhat more comprehensive mno rule of Jemmis [46]:

c The bonding within $c$ stacked compounds like e.g., $\mathrm{SrPb}_{3}$, in which $\left[\mathrm{Pb}_{6}\right]$ octahedra are fused via common corners (Figure 7), can be explained by a direct comparison with the electron-precise boride $\mathrm{CaB}_{6}$ containing also octahedral closo clusters $\mathrm{B}_{6}{ }^{2-}$ (20 v.e.), which are in this case connected via $2 \mathrm{e} 2 \mathrm{c}$ bonds (exo-bonds). Subtracting the six v.e. needed for these exo-bonds, each boron atom contributes $2 \frac{1}{3}$ v.e. to stabilize one octahedral closo cluster. In tri-tetrelides two octahedra are directly fused via corners, i.e., each $\mathrm{Pb}$ atom participates in two closo octahedral clusters. Thus, the polyanion needs $2 \times 2 \frac{1}{3}=4 \frac{2}{3}$ v.e./Pb to obey Wade's rule. This corresponds to the observed v.e. number $\left(2 \mathrm{SrPb}_{3} \longrightarrow 2 \mathrm{Sr}^{2+}+\mathrm{Pb}_{6}{ }^{4-}: 6 \times 4+4\right.$ v.e. $/$ f.u. $\equiv 4 \frac{2}{3}$ v.e. $\left./ \mathrm{Pb}\right)$. and to the fact, that the 
tDOS exhibits a very pronounced minimum close to the Fermi level, at 13.9 v.e./f.u. (bottom of Figure 12, black arrow).

$h$ The mno rules and the similarities to the 'polyaromatic' bonding in borides and molecular boranes/boranates can be also used to explain the electron count of the $h$ stacked atoms: Figure 11 shows the formal splitting of the v.e. in the boranate $\left[\mathrm{B}_{9} \mathrm{H}_{6}\right]^{-}$, which satisfies the mno rules [46] $(9+2+0=11$ s.e.p. (s.e.p.: skeleton electron pairs): $\underbrace{9 \times 3}_{\mathrm{B}}+\underbrace{6 \times 1}_{\mathrm{H}}+\underbrace{1}_{\text {charge }}-\underbrace{6 \times 2}_{\text {exo-BH }}=22$ s.e. $=11$ s.e.p.). For the formal splitting of these overall number of s.e. to individual $\mathrm{B}$ atoms, the six $\mathrm{BH}$ atoms contribute 14 s.e. $\left(6 \times 2 \frac{1}{3}\right.$, see above). The remaining 8 s.e. result in $2 \frac{2}{3}$ v.e. for each of the three central ( $h$ stacked) B atoms ( $1 \frac{1}{3}$ s.e./octahedron). Transfered to the electron balance of $\mathrm{BaSn}_{3}$, where each of the $\mathrm{Sn}$ atoms carries an additional lone-electron pair ( $s^{2}$ electrons), we expect $2+2 \frac{2}{3}=4 \frac{2}{3}$ v.e. $/ \mathrm{Sn}$ (i.e., 14 v.e. $/$ f.u.) to result in a stable cluster.
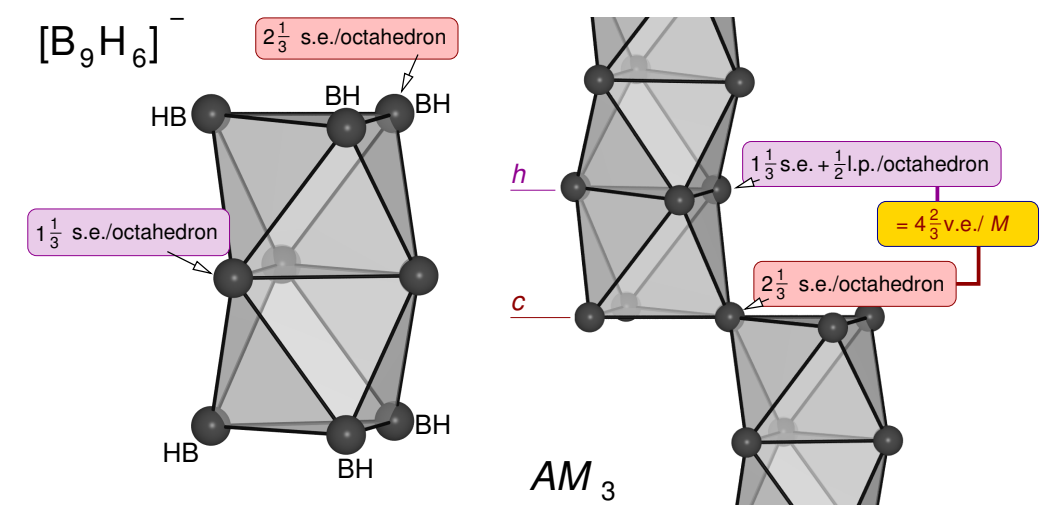

Figure 11. Explanation of the electron count proving the validity of the Wade-Jemmis mno rules for the hexagonal and cubic stacking in alkaline-earth tri-tetrelides.

The uniform ideal v.e. number for both the $h$ and $c$ stacked $M$ atoms of $4 \frac{2}{3}$ v.e./ $M$ explains the stability of the polyanion in all tri-tetrelides $A M_{3}$, i.e., for compounds with 14 v.e./f.u.

\subsubsection{Bandstructure Calculations (DOS, Electron Densities)}

In accordance with the electron count discussed above, the calculated total densities of states (tDOS) of all tri-tetrelides (cf. Figure 12 and $[10,11]$ ) exhibit distinct minima close to 14 v.e., slightly below the Fermi level. The $M$ pDOS of $c$ and $h$ layers are plotted in the familiar color code, magenta arrows indicate the position of the lone-electron pairs (l.e.p.) of the s-states of $h$-stacked $M$ atoms. The pDOS of the $M$ atoms of the polyanion are separated into overall non-bonding $M-s(-10 \ldots-4 \mathrm{eV}$, 6 v.e./f.u.) and bonding $M-p$ states ( $>-4 \mathrm{eV}, 8$ v.e./f.u.). As expected, this separation increases from the stannides to the plumbides. The low $\mathrm{Sr} / \mathrm{Ba}$ pDOS below $E_{\mathrm{F}}$ (black lines in Figure 12) is in accordance with the positive Bader charges $(q)$ of the $A$ cations and the pronounced electron transfer from the alkaline-earth element towards the $p$ block element. The cation charges vary slightly between +1.07 $\left(\mathrm{BaPb}_{3}\right)$ and $+1.26\left(\mathrm{SrSn}_{3}\right)$ (Table 4$)$. In mixed $h / c$ stacked compounds, the different $M$ atoms are comparably negatively charged, which is in agreement with the equal formal electron demand and the great importance of geometric parameters for the stacking sequences and the polyanion 'coloring'. Overall, the $M$ charges vary between -0.34 and -0.42 . 


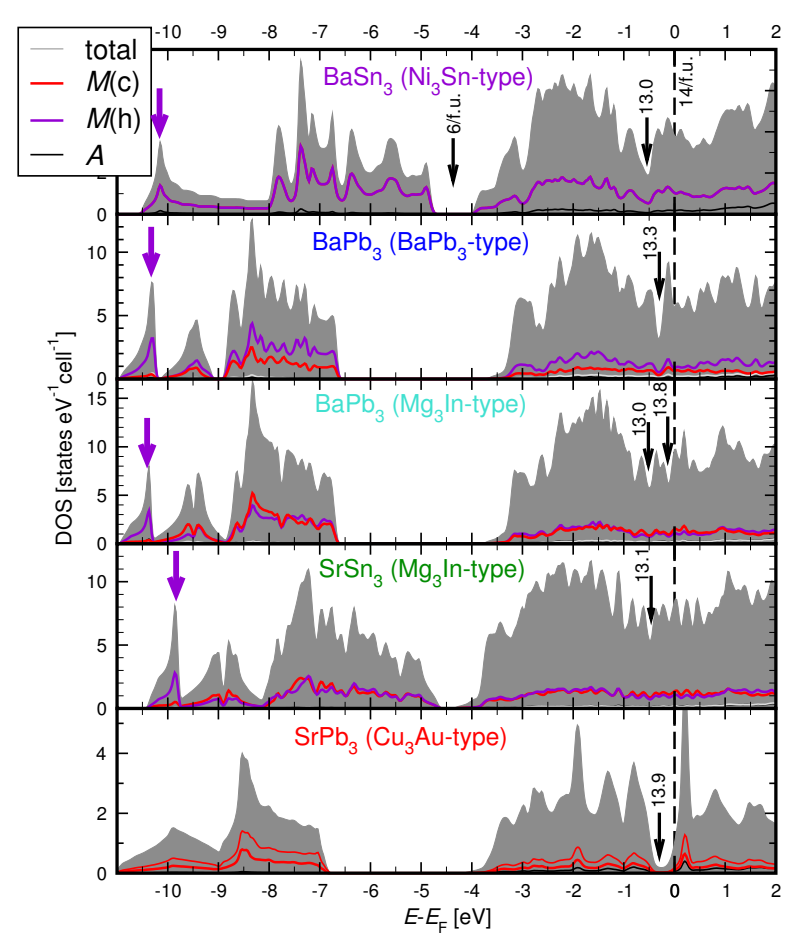

Figure 12. Density of states of the calculated alkaline-earth tri-tetrelides (in eV relative to the Fermi level; magenta/red: partial DOS of $M$ atoms of a $h / c$ layer).

The calculated electron density maps (cf. Figure 13 for a cross-section of the $h$ layer in $\mathrm{BaPb}_{3}$-II) exhibit bond (BCP) and ring (RCP) critical points of significant height $\rho_{\mathrm{BCP} / \mathrm{RCP}}\left(>0.1 \mathrm{e}^{-} 10^{-6} \mathrm{pm}^{-3}\right)$ for all labelled $M-M$ bonds. (In the tetrahedra/octahedra interstices $\rho$ drops down to $0.02 \mathrm{e}^{-} 10^{-6} \mathrm{pm}^{-3}$ ). Thereby $\rho_{\mathrm{BCP}}$ decrease with increasing $M-M$ distances (Table 4). The largest values (i.e., strongest bonds) are found for the edges of the face-sharing $\left[M_{6}\right]$ octahedra (label a in Figure 13). In the calculated ELF of both the stannides and the plumbides, only this bond (and the l.e.p.) is recognizable by a small maximum of approx. 0.6 (see also [4]). These three-membered rings are centered by distinct ring critical points of heights between 0.15 ( $\mathrm{Pb}$ compounds, cf. Figure 13) and $0.20 \mathrm{e}^{-} 10^{-6} \mathrm{pm}^{-3}$ (Sn compounds).

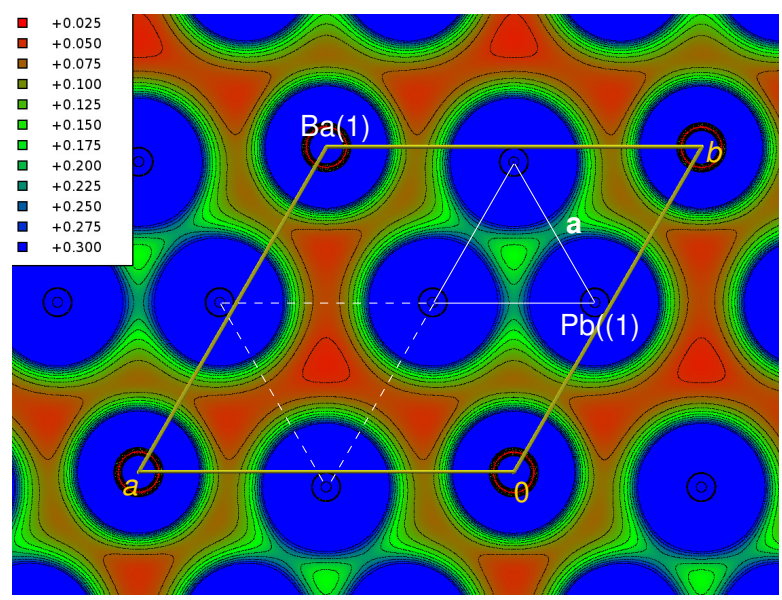

Figure 13. Cross-section of the calculated electron density map $\left[\mathrm{e}^{-} 10^{-6} \mathrm{pm}^{-3}\right]$ of the $h$ section of $\mathrm{BaPb}_{3}$-II. 
The remaining faces of all $\left[M_{6}\right]$ octahedra depicted in the structure drawings above are also centered by RCP with somewhat smaller values of $\rho_{\mathrm{RCP}}$. This and the analysis of the bandstructures of the border compounds $\mathrm{BaSn}_{3}, \mathrm{CaPb}_{3}$ and $\mathrm{BaPb}_{3}$ themselves given in the literature $[6,10,11,14,15]$ justify the description of the covalent bonding contributions in the tri-tetrelides as 'polyaromatic', i.e., as analogs of e.g., boron compounds. The $M-M$ distances, which are considerably increased compared to the single bond lengths, are also similar to the larger contacts observed e.g., in the electron-precise nido clusters $\mathrm{M}_{9}{ }^{4-}$ of several alkali stannides/plumbides [47-52].

Nevertheless, polar compounds of this structure family are known to be electronically somewhat flexible and the minimum of the tDOS generally does not exactly coincide with the Fermi level. The comparison of the tDOS of tri-tetrelides with varying $h / c$ stacking ratio displays tendencies towards a small decrease of the tDOS minimum with increasing $h$-stacked layers (cf. black arrows in Figure 12). A similar trend is obvious in the tin series $\mathrm{CaSn}_{3} / \mathrm{SrSn}_{3} / \mathrm{BaSn}_{3}$, where the tDOS minima are found at 13.9/13.3/13 v.e./f.u. [10]. This shift is in accordance with several experimental observations [7,12,15], e.g., for Tl-substituted plumbides [16] and the series $\mathrm{BaBi}_{3}-\mathrm{BaSn}_{3}$ [18]: in both cases, the amount of $h$ stacked layers increases continuously with decreasing v.e. numbers.

\section{Summary}

The reported systematic experimental, crystallographic and bond-theoretical DFT study of the series of mixed $\mathrm{Sn} / \mathrm{Pb}(M)$ tri-tetrelides of $\mathrm{Sr}$ and $\mathrm{Ba}(A) A M_{3}$ allows the study of the geometric and electronic criteria, which determine the stacking sequences of planar $A M_{3}$ hexagonal layers in the large family of close-packed $\mathrm{AB}_{3}$ structures. The series of new compounds starts at the binary tri-stannide $\mathrm{BaSn}_{3}$ with a pure hexagonal $h_{2}$ stacking ( $\mathrm{NiSn}_{3}$-type), in which up to $28 \%$ of the $\mathrm{Sn}$ atoms can be substituted against $\mathrm{Pb}$. A further increased lead content of 47 to $66 \%$ causes the formation of the $\mathrm{BaSn}_{2.6} \mathrm{Bi}_{0.4}$-type structure with a $(h h h c)_{2}$ stacking. The stability range of the $\mathrm{BaPb}_{3}$-type sequence $(h h c)_{3}$ starts at a lead proportion of $78 \%$ and reaches up to the pure plumbide $\mathrm{BaPb}_{3}$. A second new polymorph of $\mathrm{BaPb}_{3}$ forms the $\mathrm{Mg}_{3}$ In-type structure with a further increased amount of cubic sequences $\left[(h h c c)_{3}\right]$ and is thus isotypic with the border phase $\mathrm{SrSn}_{3}$ of the respective Sr series. In this series, a Pb content of 32 to $41 \%$ creates an existence region of the $\mathrm{PuAl}_{3}$-type with a $(h c c)_{2}$ stacking. The series is terminated by the pure $c$ stacking of $\mathrm{SrPb}_{3}\left(\mathrm{Cu}_{3} \mathrm{Au}\right.$-type), which starts at $75 \% \mathrm{~Pb}$. Even though all compounds are metals, the calculated DOS exhibits pronounced pseudo band gaps slightly below $E_{\mathrm{F}}$ of 14 v.e./f.u. The minimum occurs independent of the type of stacking, so that geometric parameters (radius ratio of the atoms/cations) are the main parameters determining the layer sequence. The application of simple covalent bonding concepts (Zintl concept and Wade/Jemmis mno rules), which is justified by the distinct bond and ring critical points of the electron density maps, the features of the ELFs and the band structures themselves, allows for the explanation of these DOS minima at approx. 14 v.e./f.u. Nevertheless, metallic (i.e., steep bands crossing $E_{\mathrm{F}}$ ) besides the covalent (flat bands near $E_{\mathrm{F}}$ ) features are the main characteristic of the band structures of the tri-tetrelides and determine their specific physical properties like e.g., their superconductivity.

Author Contributions: Compound synthesis: M.L. and M.J.; Data collection (powder and single crystal): M.L. and M.J.; Structure refinements: M.L., M.J. and C.R.; Theoretical calculations: M.L., M.J. and C.R.; Writing: M.L., M.J. and C.R.

Acknowledgments: We would like to thank the Deutsche Forschungsgemeinschaft for financial support.

Conflicts of Interest: The authors declare no conflict of interest.

\section{References and Notes}

1. Fässler, T.F.; Hoffmann, S. Valence compounds at the border to intermetallics: alkali and alkaline earth metal stannides and plumbides. Z. Kristallogr. 1999, 214, 722-734. [CrossRef]

2. Hume-Rothery, W. Formation of intermetallic compounds. Part IV: The System Calcium-Tin and the compounds $\mathrm{CaSn}_{3}, \mathrm{CaSn}$ and $\mathrm{Ca}_{2} \mathrm{Sn}$. J. Inst. Met. 1926, 35, 319-335. 
3. Fässler, T.F.; Hoffmann, S. $\mathrm{SrSn}_{3}$-eine supraleitende Legierung mit freien Elektronenpaaren. Z. Anorg. Allg. Chem. 2000, 626, 106-112. [CrossRef]

4. Ray, K.W.; Thompson, R.G. Study of barium-tin alloys. Met. Alloys 1930, 1, 314-316.

5. Fässler, T.F.; Kronseder, C. $\mathrm{BaSn}_{3}$, ein Supraleiter im Grenzbereich zwischen Zintl-Phasen und intermetallischen Verbindungen: Realraumanalyse von Bandstrukturen. Angew. Chem. 1997, 109, 2800-2803. [CrossRef]

6. Damsma, W.; Havinga, E.E. Influence of small lattice deformation on the superconductive critical temperature of alloys with the $\mathrm{Cu}_{3} \mathrm{Au}$ type structure. J. Phys. Chem. Solids 1972, 34, 813-816. [CrossRef]

7. Van Vucht, J.H.N. Influence of radius ratio on the structure of intermetallic compounds of the $\mathrm{AB}_{3}$ type. J. Less Common Met. 1966, 11, 308-322. [CrossRef]

8. Havinga, E.E. Influence of repulsive energy on structural parameters of the close-packed metal structures. J. Less Common Met. 1975, 41, 241-254. [CrossRef]

9. Sands, D.E.; Wood, D.H.; Ramsey, W.J. The structures of $\mathrm{Ba}_{5} \mathrm{~Pb}_{3}, \mathrm{BaPb}$ and $\mathrm{BaPb}_{3}$. Acta Crystallogr. 1964, 17, 986-989. [CrossRef]

10. Wendorff, M.; Röhr, C. Gemischte Tristannide der Reihe $\mathrm{CaSn}_{3}-\mathrm{SrSn}_{3}-\mathrm{BaSn}_{3}$ : Synthesen, Kristallstrukturen, Chemische Bindung. Z. Anorg. Allg. Chem. 2011, 637, 1013-1023. [CrossRef]

11. Wendorff, M.; Röhr, C. Gemischte Plumbide $(\mathrm{Ca} / \mathrm{Sr})_{x} \mathrm{Ba}_{1-\mathrm{x}} \mathrm{Pb}_{3}$. Strukturchemie und chemische Bindung. Z. Naturforsch. 2008, 63b, 1383-1394.

12. Havinga, E.E. W-like dependence of critical temperature on number of valence electrons in non-transition metal $\mathrm{Cu}_{3} \mathrm{Au}$-type alloys. Phys. Lett. A 1968, 28, 350-351. [CrossRef]

13. Havinga, E.E.; Damsma, W.; van Maaren, M.H. Oscillatory dependence of superconductive critical temperature on number of valency electrons in $\mathrm{Cu}_{3} \mathrm{Au}$ type alloys. J. Phys. Chem. Solids 1970, 31, 2653-2662. [CrossRef]

14. Baranovskiy, A.E.; Grechnev, G.E.; Svechkarev, I.V. Features of the electronic spectrum and anomalous magnetism in the compounds $\mathrm{YbPb}_{3}, \mathrm{YbSn}_{3}, \mathrm{CaPb}_{3}$ and $\mathrm{CaSn}_{3}$. Low Temp. Phys. 2006, 32, 849-856. [CrossRef]

15. Baranovskiy, A.E.; Grechnev, G.E.; Mikitik, G.P.; Svechakarev, I.V. Anomalous diamagnetism in the intermetallic compounds $\mathrm{CaPb}_{3}$ and $\mathrm{YbPb}_{3}$. Low Temp. Phys. 2003, 29, 356-358. [CrossRef]

16. Havinga, E.E.; van Vucht, J.H.N. The crystal structure of $\mathrm{Ba}\left(\mathrm{Pb}_{0.8} \mathrm{Tl}_{0.2}\right)_{3}$. Acta Crystallogr. 1970, B26, 653-655. [CrossRef]

17. Single crystal structure refinement of the strucuture of $B a \operatorname{In}_{0.15} \mathrm{~Pb}_{2.85}$ : Hexagonal, space group $P 6_{3} / m m c$, $a=733(1), c=3991(5) \mathrm{pm}, Z=14, R 1=0.0494$.

18. Ponou, S.; Fässler, T.F.; Kienle, L. Structural complexity in intermetallic alloys: Long-periodic order beyound $10 \mathrm{~nm}$ in the system $\mathrm{BaSn}_{3} / \mathrm{BaBi}_{3}$. Angew. Chem. 2008, 47, 3999-4004. [CrossRef] [PubMed]

19. Miller, G.J. The "Coloring Problem" in solids: How it affects structure, composition and properties. Eur. J. Inorg. Chem. 1998, 5, 523-536. [CrossRef]

20. Yvon, K.; Jeitschko, W.; Parthé, E. Program LAZY-PULVERIX; University Geneve: Geneva, Switzerland, 1976.

21. STOE \& Cie GmbH. X-SHAPE (Version 1.03), Crystal Optimization for Numerical Absorption Correction; STOE \& Cie GmbH: Darmstadt, Germany, 2005.

22. Sheldrick, G.M. SADABS: Program for Absorption Correction for Data from Area Detector Frames; Bruker Analytical X-ray Systems, Inc.: Madison, WI, USA, 2008.

23. Sheldrick, G.M. A short history of SHELX. Acta Crystallogr. 2008, A64, 112-122. [CrossRef] [PubMed]

24. Gelato, L.M.; Parthé, E. STRUCtURE TIDY: A computer program to standardize structure data. J. Appl. Crystallogr. 1990, A46, 467-473. [CrossRef]

25. Further details on the crystal structure investigation are available from the Fachinformationszentrum Karlsruhe, Gesellschaft für wissenschaftlich-technische Information mbH, D-76344 Eggenstein-Leopoldshafen 2 on quoting the depository numbers CSD $431093\left(\mathrm{BaPb}_{3}-\mathrm{II}\right), 431094\left(\mathrm{BaSn}_{0.65} \mathrm{~Pb}_{2.35}\right) 431095\left(\mathrm{BaSn}_{1.01} \mathrm{~Pb}_{1.99}\right) 431096$ $\left(\mathrm{BaSn}_{1.52} \mathrm{~Pb}_{1.42}\right) 431097\left(\mathrm{BaSn}_{2.20} \mathrm{~Pb}_{0.80}\right)$ and $431098\left(\mathrm{SrSn}_{2.05} \mathrm{~Pb}_{0.95}\right)$, the names of the authors, and citation of the paper (E-mail: crysdata@fiz-karlsruhe.de).

26. Larson, A.C.; Dreele, R.B.V. General Structure Analysis System (GSAS); Los Alamos National Laboratory Report LAUR 86-748; Los Alamos National Laboratory: Los Alamos, NM, USA, 2000.

27. Toby, B.H. EXPGUI, a graphical user interface for GSAS. J. Appl. Crystallogr. 2001, 34, 210-221. [CrossRef]

28. Schubert, K.; Gauzzi, F.; Frank, K. Kristallstruktur einiger Mg-B3-Phasen. Z. Metallk. 1963, 54, $422-429$. 
29. Blaha, P.; Schwarz, K.; Madsen, G.K.H.; Kvasnicka, D.; Luitz, J. WIEN2K, An Augmented Plane Wave and Local Orbital Program for Calculating Crystal Properties; TU Wien: Vienna, Austria, 2006; ISBN3-9501031-1-2.

30. Dewhurst, J.K.; Sharma, S.; Nordstrom, L.; Cricchio, F.; Bultmark, F.; Gross, E.K.U. ElK (Vers. 2.1.15), The Elk-FP-LAPW Code. 2013. Available online: http:/ / elk.sourceforge.net (accessed on 5 May 2018).

31. Perdew, J.P.; Burke, S.; Ernzerhof, M. Generalized gradient approximation made simple. Phys. Rev. Lett. 1996, 77, 3865-3868. [CrossRef] [PubMed]

32. Miller, G.J.; Zhang, Y.; Wagner, F.R. Chemical bonding in solids. In Handbook of Solid State Chemistry; Dronskoski, R., Kikkawa, S., Stein, A., Eds.; Wiley-VCH: Weinheim, Germany, 2017; Volume 5, pp. 405-489.

33. Savin, A.; Nesper, R.; Wengert, S.; Fässler, T.F. ELF: The electron localization function. Angew. Chem. Int. Ed. 1997, 36, 1808-1832. [CrossRef]

34. Kokalj, A. Program XCRYSDEN. J. Mol. Graph. Model. 1999, 17, 176-178. [CrossRef]

35. Finger, L.W.; Kroeker, M.; Toby, B.H. DRAWXTL: An open-source computer program to produce crystal structure drawings. J. Appl. Crystallogr. 2007, 40, 188-192. [CrossRef]

36. Bader, R.W.F. Atoms in Molecules. A Quantum Theory; International Series of Monographs on Chemistry; Clarendon Press: Oxford, UK, 1994.

37. De-la Roza, A.O.; Blanco, M.A.; Martá, A.; Pendás, A.M.; Luaña, V. Program Critic2 (Vers. 1.0). Comput. Phys. Commun. 2009, 180, 157-166.

38. De-la Roza, A.O.; Luaña, V. A fast and accurate algorithm for QTAIM integrations in solids. J. Comput. Chem. 2010, 32, 291-305. [CrossRef] [PubMed]

39. FIZ Karlsruhe. Inorganic Crystal Structure Database; FIZ Karlsruhe: Karlsruhe, Germany, 2017.

40. Cirafici, S.; Franceschi, E. Stacking of close-packed $\mathrm{AB}_{3}$ layers in $\mathrm{RGa}_{3}$ compounds ( $\mathrm{R}=$ heavy rare earth). J. Less Common Met. 1981, 77, 269-280. [CrossRef]

41. Larson, A.C.; Cromer, D.T.; Stambaugh, C.K. The crystal structure of $\mathrm{PuAl}_{3}$. Acta Crystallogr. 1957, 10, 443-446. [CrossRef]

42. Shannon, R.D. Revised effective ionic radii and systematic studies of interatomic distances in halides and chalcogenides. Acta Crystallogr. 1976, A32, 751-767. [CrossRef]

43. Pearson, W.B. The Crystal Chemistry and Physics of Metals and Alloys; Wiley Interscience: Hoboken, NJ, USA, 1972.

44. Wendorff, M.; Röhr, C. Alkaline-earth tri-mercurides $A^{I I} \mathrm{Hg}_{3}\left(A^{I I}=\mathrm{Ca}, \mathrm{Sr}, \mathrm{Ba}\right)$ : Binary intermetallic compounds with a common and a new structure type. Z. Kristallogr. 2018, in press.

45. Wade, K. Structural and bonding patterns in cluster chemistry. Adv. Inorg. Chem. Radiochem. 1976, 18, 1.

46. Jemmis, E.D.; Balakrishnarajan, M.M.; Pancharatna, P.D. Electronic requirements for macropolyhedral boranes. Chem. Rev. 2002, 102, 93-144. [CrossRef] [PubMed]

47. Todorov, E.; Sevov, S.C. Deltahedral clusters in neat solids: Synthesis and structure of the Zintl phase $\mathrm{Cs}_{4} \mathrm{~Pb}_{9}$ with discrete $\mathrm{Pb}_{9}^{4-}$ clusters. Inorg. Chem. 1998, 37, 3889-3891. [CrossRef] [PubMed]

48. Fässler, T.F. The renaissance of homoatomic nine-atom polyhedra of the heavier carbon-group element $\mathrm{Si}-\mathrm{Pb}$. Coord. Chem. Rev. 2001, 215, 347-377. [CrossRef]

49. Hoch, C.; Röhr, C.; Wendorff, M. Crystal structure of $\mathrm{K}_{4} \mathrm{Sn}_{9}$. Acta Crystallogr. 2002, C58, 45-46.

50. Bobev, S.; Sevov, S.C. Isolated deltaheral clusters of leadin the solid state: synthesis and characterization of $\mathrm{Rb}_{4} \mathrm{~Pb}_{9}$ and $\mathrm{Cs}_{10} \mathrm{~K}_{6} \mathrm{~Pb}_{36}$ with $\mathrm{Pb}_{9}^{4-}$, and $\mathrm{A}_{3}^{\prime} \mathrm{A}^{\prime \prime} \mathrm{Pb}_{4}\left(\mathrm{~A}^{\prime}=\mathrm{Cs}, \mathrm{Rb}, \mathrm{K} ; \mathrm{A}^{\prime \prime}=\mathrm{Na}\right.$, Li) with $\mathrm{Pb}_{4}^{4-}$. Polyhedron 2002, 21, 641-649. [CrossRef]

51. Fässler, T.F.; Hunziker, M. The nido- $\mathrm{Pb}_{9}^{4-}$ and the Jahn-Teller Distorted closo-Pb ${ }_{9}^{3-}$ Zintl-Anions: Syntheses, X-ray Structures and Theoretical Studies. Inorg. Chem. 1995, 33, 5798-5809.

52. Hoch, C.; Wendorff, M.; Röhr, C. Synthesis and Crystal Structure of the Plumbides $\mathrm{A}_{4} \mathrm{~Pb}_{9}$ and the Tetrelides $\mathrm{A}_{12} \mathrm{M}_{17}(\mathrm{~A}=\mathrm{Na}, \mathrm{K}, \mathrm{Rb}, \mathrm{Cs} ; \mathrm{M}=\mathrm{Si}, \mathrm{Ge}, \mathrm{Sn})$. J. Alloys Compd. 2003, 361, 206-221. [CrossRef]

(C) 2018 by the authors. Licensee MDPI, Basel, Switzerland. This article is an open access article distributed under the terms and conditions of the Creative Commons Attribution (CC BY) license (http:/ / creativecommons.org/licenses/by/4.0/). 